KATIA CRISTINA GARCIA NUNES DE SOUZA

MODELO DE GESTÃO DE ESTOQUES PARA BENS DE CONSUMO EM SUPERMERCADOS

Dissertação apresentada à Escola

Politécnica da Universidade de São Paulo para obtenção do título de Mestre em

Engenharia de Sistemas Logísticos 
KATIA CRISTINA GARCIA NUNES DE SOUZA

\section{MODELO DE GESTÃO DE ESTOQUES PARA BENS DE CONSUMO EM SUPERMERCADOS}

Dissertação apresentada à Escola

Politécnica da Universidade de São Paulo para obtenção do título de Mestre em

Engenharia de Sistemas Logísticos

Área de Concentração:

Engenharia de Sistemas Logísticos

Orientador: Prof Miguel Cezar Santoro 
Este exemplar foi revisado e alterado em relação à versão original, sob responsabilidade única do autor e com a anuência de seu orientador.

São Paulo, 16 de março de 2012.

Assinatura do autol

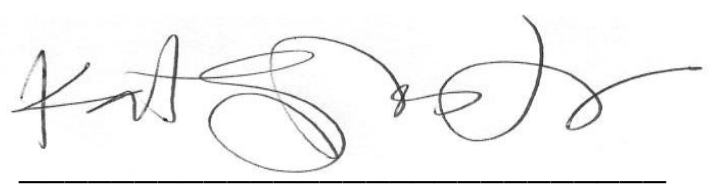

Assinatura do orientador

Souza, Kátia Cristina Garcia Nunes de

Modelo de gestão de estoques para bens de consumo em supermercados / K.C.G.N. de Souza. - ed.rev. -- São Paulo, 2012. $107 \mathrm{p}$.

Dissertação (Mestrado) - Escola Politécnica da Universidade de São Paulo. Departamento de Engenharia de Produção.

1. Administração de estoques 2. Sistemas de apoio a decisão 3. Demanda (Previsão) I. Universidade de São Paulo. Escola Politécnica. Departamento de Engenharia de Produção II. t. 


\section{DEDICATÓRIA}

À minha querida mãe Jonete, eterna referência de perseverança, obstinação e humildade.

À minha avó Alair, que sempre fará parte de todas as minhas vitórias. 


\section{AGRADECIMENTOS}

Muitos colaboraram direta ou indiretamente para que esse trabalho fosse possível. Gostaria de destacar aqui aqueles que foram os mais importantes nesta longa jornada.

Ao Professor Miguel Santoro, pelo indiscutível suporte e bom-humor, sempre dedicado a desenvolver em seus alunos senso crítico e questionador sobre os textos teóricos. Esse período de convívio foi para mim uma honra e uma oportunidade única de vivência e aprendizado.

À minha família, pelo extraordinário apoio e envolvimento, e por aguentar minha eterna ausência e indisponibilidade porque, como eu, acreditaram neste sonho e na importância deste projeto para minha vida.

A todos os meus amigos que já desistiram de me ligar, embora não tenham desistido de nossa amizade. 


\section{RESUMO}

Este trabalho analisa a viabilidade de aplicação de uma sistemática de gestão de estoques que permite escolher e parametrizar modelos de decisão de reposição de itens para apoiar os coordenadores de abastecimento de supermercados, através da utilização de dados reais. O principal objetivo desta sistemática é contribuir para o aumento da disponibilidade de produtos na loja do supermercado, através do seguinte equacionamento: minimizar os custos operacionais e de estoque do varejo, tendo como restrição um nível mínimo de serviço ao cliente. Esta pesquisa experimental aplicada possibilitou identificar que o modelo CALNEC apresentou o melhor desempenho em $80 \%$ da amostra. A melhor configuração (configuração dos melhores desempenhos de todos os modelos) ofereceu uma economia de até $42 \%$ frente ao custo atual. $\mathrm{O}$ modelo de gestão de estoque atualmente utilizado apresentou desempenho pior mesmo comparado aos modelos não vencedores.

Palavras-chave: Rupturas. Gestão de estoques. Previsão de demanda. Modelo de apoio à decisão. Varejo. 


\begin{abstract}
This work analyses the viability of an application of the inventory management systematic, which allows to choose and to parameterize replenishment decision models to support supermarket replenishment coordinators in their tasks, using real data. The main objective of this systematic is to contribute to the product availability improvement in the supermarket store considering the following equation: minimize the operational and inventory costs from retail having as a restriction the minimum customer service level in items available at the retail store. This experimental applied research identified CALNEC as the inventory model that presented the best performance in $80 \%$ of the sample. The best configuration (configuration of the best performance from all models) showed a saving of $42 \%$ compared to the current costs. The current inventory management model presented the worst performance even compared to the non-winners models.
\end{abstract}

Keywords: Out-of-stocks. Inventory management. Demand forecast. Decision support model. Retail. 


\section{LISTA DE FIGURAS}

Figura 2.1 Causas de rupturas: médias mundiais........................................ 09

Figura 2.2 Resposta mundial do consumidor às rupturas - média das 8

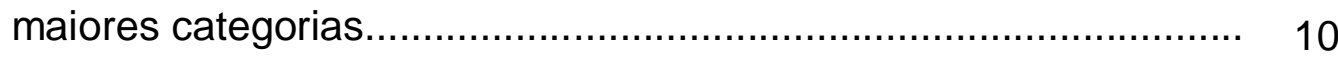

Figura 2.3 Reação do consumidor brasileiro diante da ruptura do produto........ 11

Figura 2.4 Resultado das rupturas dos itens em gôndola em \% no varejo em período de 12 meses..................................................................... 12

Figura 2.5 Ciclo do pedido de SKUs regulares e atividades promocionais........ 16

Figura 2.6 Fluxograma para identificação das causas-raízes de ruptura na

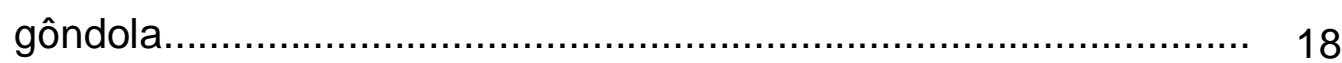

Figura $3.1 \quad$ O processo de previsão............................................................ 25

Figura 4.1 O problema físico do estoque...................................................... 45

Figura 4.2 Relacionamento entre as decisões............................................. 45

Figura 4.3 Operação do modelo ativo......................................................... 51

Figura 6.1 Arranjo experimental utilizado no SGE....................................... 61

Figura 6.2 Regra de correção das vendas com avaliação das faltas................. 67

Figura 6.3 Autocorrelograma para SKU2 na Loja 3.................................... 71 


\section{LISTA DE TABELAS}

Tabela 1.1 Composição e função dos canais de distribuição da indústria..... 04

Tabela 1.2 Tamanho, quantidade de SKUs e foco dos formatos de Ioja.

Tabela 2.1 Representatividade das causas-raízes das rupturas.

Tabela 3.1 Padrão da série histórica x técnica de previsão.

Tabela 3.2 Gerentes de manufatura x técnicas de previsão de demanda. 31

Tabela 4.1 Funcionalidade do inventário. 39

Tabela 4.2 Classificação dos modelos de estoques 40

Tabela 4.3 Exemplos de modelos de estoque. 46

Tabela 6.1 Classificação das lojas da amostra. 63

Tabela 6.2 Critério para classificação das lojas. 64

Tabela 6.3 Classificação dos SKUs da amostra. 64

Tabela 6.4 Critério para classificação dos SKUs. 65

Tabela 6.5 Resultado da análise de situações encontradas na amostra. 66

Tabela 6.6 Resumo da análise de autocorreção p/ combinações SKU x loja..... 71

Tabela 6.7 Métodos de suavização e seus parâmetros. 76

Tabela 6.8 Referência de cálculo para valores iniciais de parâmetros... 79

Tabela 6.9 Exemplo de relatório de saída do SGE.

Tabela 7.1 Resultado consolidado do desempenho dos modelos de reposição de estoque por \% de cada um dentre cada classificação

Tabela 7.2 Resultado consolidado dos modelos de projeção por SKU. 82

Tabela 7.3 Resultado detalhado dos custos de cada modelo por classificação.

Tabela 7.4 Percentual do modelo vencedor por SKU x loja.

Tabela 7.5 Resultado detalhado dos custos dos modelos vencedores por SKU 85

Tabela 7.6 Percentual do modelo vencedor por loja. 85

Tabela 7.7 Resultado detalhado dos custos dos modelos vencedores por loja.. 85 Tabela 7.8 Resultado em \% de SKU x loja da análise de sensibilidade para 
diferentes níveis de serviço classificados por modelo...................... 87

Tabela 7.9 Resultado em custos da análise de sensibilidade para diferentes níveis de serviço classificados por modelo..................................... 88 


\section{LISTA DE SIGLAS}

ABRAS

CALNEC

CD

ECR

EDI

EstFis

EstFisARec

EstMax $=\mathrm{S}$

EstSeg

$\mathrm{KPI}$

LotFix $=Q=q$

LOTFIXC

LOTFIXP

MAD

MAPE

MSE

MPE

MRP

NLiq

OCompra

PerRev $=\mathrm{R}$

PreDem

PtoPed $=\mathrm{s}$

REPBASC

REPBASP

REPMAXC

REPMAXP

SGE

SKU

VBA
Associação Brasileira de Supermercados

Cálculo de Necessidades

Centro de Distribuição

Efficient Consumer Response

Eletronic Data Interchange

Estoque Físico

Estoque Físico a Receber

Estoque Máximo

Estoque de Segurança

Key Performance Indicators

Lote fixo

Reposição por Lote fixo contínuo

Reposição por Lote fixo periódico

Mean Absolute Deviation

Mean Absolute Percentage Error

Mean Squared Error

Mean Percentage Error

Material Requirement Planning

Necessidade Líquida

Ordem de Compra

Período de Revisão

Previsão de Demanda

Ponto de Pedido

Reposição da base contínuo

Reposição da base periódico

Reposição do máximo contínuo

Reposição do máximo periódico

Sistema de Gerenciamento de Estoque

Stock Keeping Unit

Visual basic for applications 


\section{SUMÁRIO}

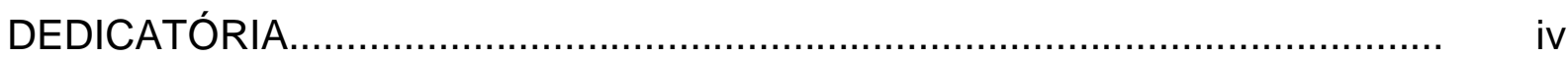

AGRADECIMENTOS........................................................................... v

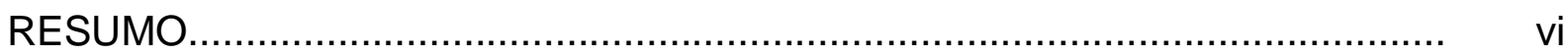

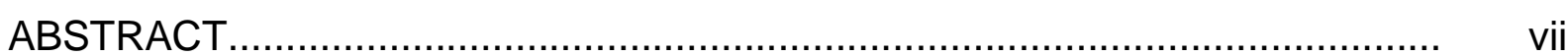

LISTA DE FIGURAS................................................................................. viii

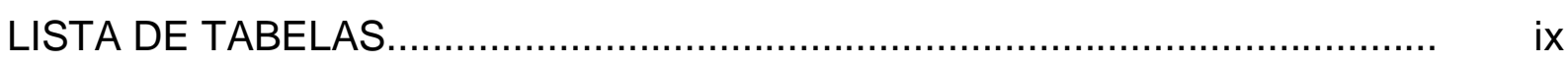

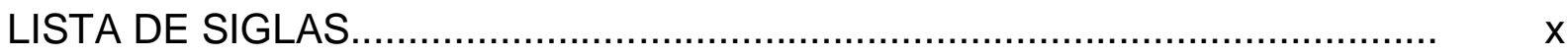

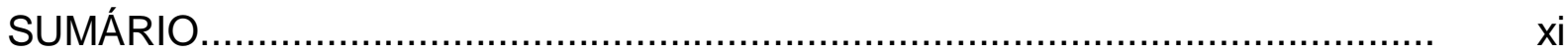

1 INTRODUÇÃO

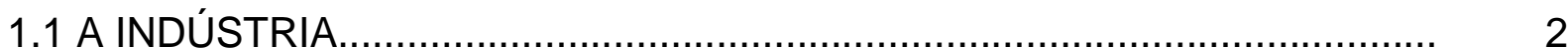

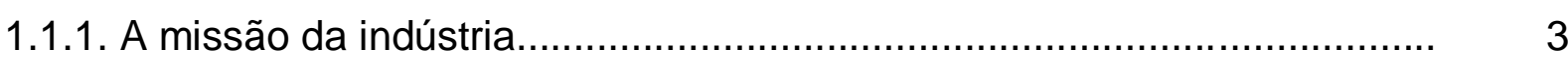

1.1.2. Canais de distribuição...................................................................... 4

1.1.3 Estratégia do negócio..................................................................

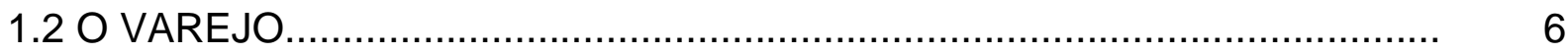

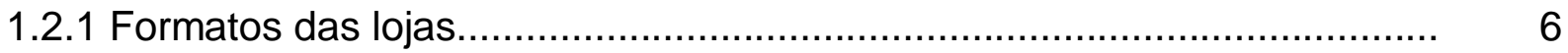

1.2.2 Estratégia do negócio......................................................................

2 DESCRIÇÃO DO PROBLEMA............................................................. 8

2.1 A RUPTURA DE ESTOQUE................................................................. 8

2.1.1 O impacto da ruptura de estoque no varejo............................................. 11

2.2 PROCESSO DE ABASTECIMENTO DO VAREJO...................................... 13

2.2.1 Os atores: papéis e responsabilidades.................................................. 13

2.2.1.1 Equipe da indústria................................................................... 13

2.2.1.2 Equipe do varejo........................................................................ 14

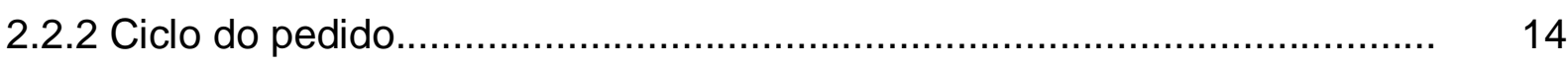

2.2.3 As causas raízes da ruptura de estoque................................................ 17

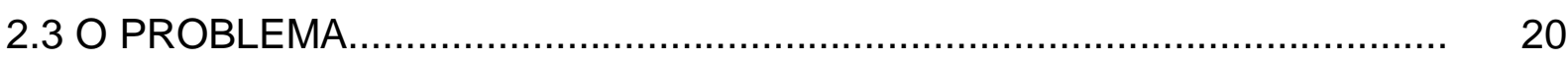

2.4 O OBJETIVO DO TRABALHO............................................................... 21

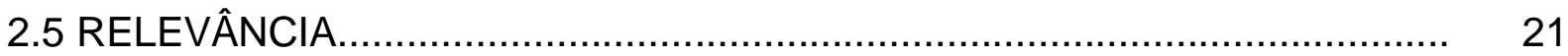

3 REVISÃO BIBLIOGRÁFICA - PREVISÃO DE DEMANDA............................. 23

3.1 DEFINIÇÃO E PROPÓSITO............................................................. 23 
3.2 MÉTODOS DE PREVISÃO...

3.2.1 Classificação dos métodos de previsão...................................................... 26

3.2.2 Fatores de escolha do método de previsão............................................ 27

3.2.3 Padrões de demanda........................................................................... 27

3.2.4 Definição de autocorrelação............................................................... 28

3.2.5 Métodos de previsão de demanda............................................................. 30

3.2.5.1 Métodos baseados em médias........................................................ $\quad 30$

3.2.5.2 Métodos baseados em suavização.................................................... 31

3.2.6 Medição de erros nas previsões........................................................ 34

4 REVISÃO BIBLIOGRÁFICA - GESTÃO DE ESTOQUES.............................. 36

4.1 DEFINIÇÃO E PROPÓSITO................................................................... 36

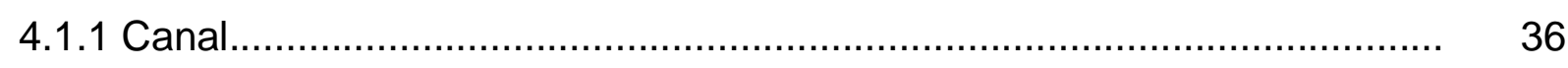

4.1.2 Especulação.............................................................................. 37

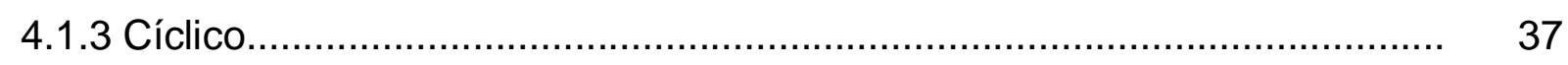

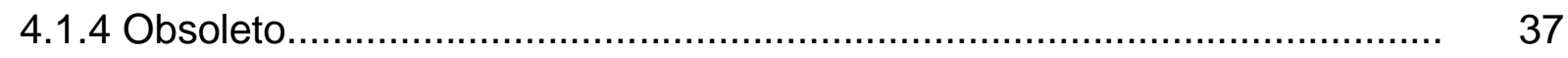

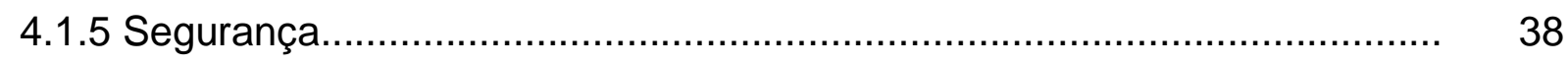

4.2 CUSTOS DOS ESTOQUES............................................................. 41

4.2.1 Custos de aquisição............................................................................ 41

4.2.2 Custos de manutenção de estoque...................................................... 42

4.2.2.1 Custos de estocagem e manuseio.................................................... 42

4.2.2.2 Custos de capital...................................................................... 42

4.2.2.3 Custos de serviços e riscos de estocagem............................................. 43

4.2.3 Custos de falta de estoque................................................................. 43

4.3 COMPOSIÇÃO DE UM SISTEMA DE GESTÃO DE ESTOQUE.................. 44

4.4 MODELOS DE REPOSIÇÃO DE ESTOQUE........................................... 45

4.4.1 Modelos reativos.................................................................................. 46

4.4.1.1 REPMAXP - Reposição do Máximo periódico..................................... 47

4.4.1.2 REPMAXC - Reposição do Máximo contínuo....................................... 47

4.4.1.3 REPBASP e REPBASC - Reposição da base periódico e contínuo....... 48

4.4.1.4 Lote fixo períodico e contínuo............................................................. 49

4.4.2 Modelo ativo.................................................................................... 50

4.4.2.1 Cálculo das necessidades............................................................... 50

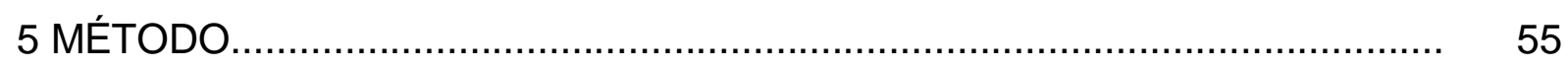


6 PROCEDIMENTO EXPERIMENTAL_....................................................... 56

6.1 SELEÇÃO DA AMOSTRA DE TRABALHO............................................... 62

6.1.1 Critérios para seleção das lojas......................................................... 62

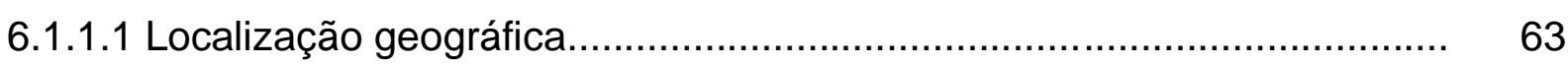

6.1.1.2 Classificação por volume de venda...................................................... 63

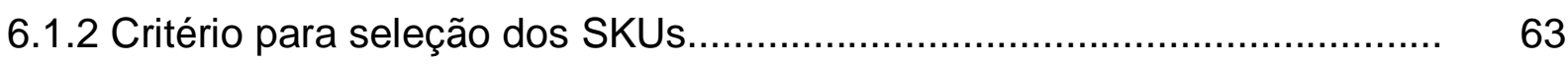

6.1.2.1 Classificação por volume de venda..................................................... 65

6.2 TRATAMENTO DOS DADOS........................................................... 65

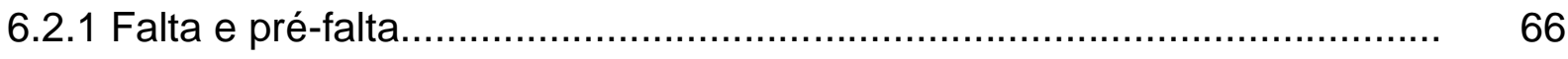

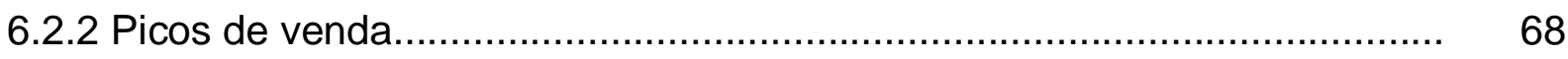

6.2.3 Venda negativa, estoque negativo ou venda com estoque zerado............. 69

6.3 ANÁLISE DE PADRÕES DOS DADOS................................................... $\quad 70$

6.3.1 Autocorrelogramas e padrões de dados................................................ $\quad 70$

6.3.2 Resultados da análise de autocorrelação................................................... 71

6.4 MODELO DE GESTÃO DE ESTOQUES.............................................. 72

6.4.1 Indicadores de desempenho .......................................................... 72

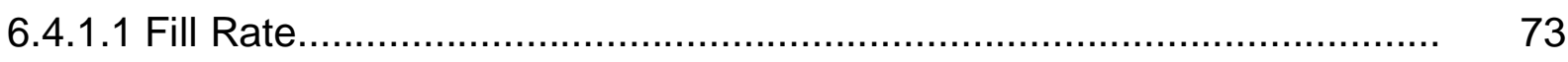

6.4.1.2 Custo operacional.......................................................................... 73

6.4.2 O modelo atual de gestão de estoques do varejo...................................... 74

6.4.3 Parametrização do módulo............................................................... $\quad 74$

6.4.4 Rotina de busca e simulação para modelos de previsão............................ 75

6.4.5 Rotina de busca e simulação para modelos de estoque.............................. 78

7 DISCUSSÃO DOS RESULTADOS ……………................................. 81

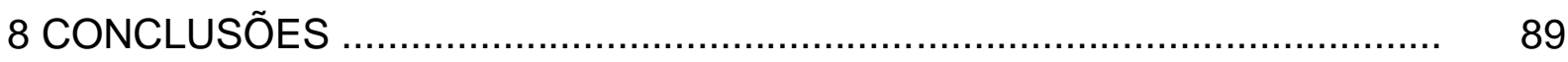

9 REFERÊNCIAS BIBLIOGRÁFICAS ............................................................ 91 


\section{INTRODUÇÃO}

Rupturas são entendidas pela Associação Efficient Consumer Response (ECR) como a falta de produto na gôndola do ponto de venda no momento em que o consumidor ali o procura.

Em outras palavras, todos os produtos do mix regular de vendas da empresa deveriam estar sempre à disposição do consumidor no ponto de venda.

Os principais atores desta cadeia são a indústria e o varejo, tradicionais parceiros que mantêm entre si uma relação de simbiose, pois dependem um do outro para o atingimento de seus principais objetivos de negócio.

Assim, a indústria necessita da capilarização do varejo para construção e perpetuação de suas marcas, enquanto o varejo necessita das marcas desenvolvidas pela indústria, de seu conhecimento e de investimentos para garantir tráfego em suas lojas.

Ambos operam de forma conectada, uma vez que pertencem a mesma cadeia de suprimento, que se inicia no planejamento de vendas da indústria e finaliza-se na exposição dos produtos na gôndola do varejo.

Segundo estudo de Gruen, Corsten e Bharadwaj (2002), os principais riscos causados pelas rupturas no varejo incluem perdas de venda relacionadas à troca de loja pelo consumidor que não encontrou o item procurado, ou mesmo troca de produto ou marca, resultando em perda de venda para a indústria.

Em ambos os casos, os autores demonstraram que há impacto nas relações de fidelidade do consumidor com a marca e com a loja - em função do número total de visitas de compra e itens em ruptura, da frequência com a qual o consumidor experimenta as rupturas em tais itens, e da importância destes para este consumidor. 
Este mesmo estudo concluiu que em cerca de $47 \%$ dos casos a causa-raiz das rupturas está relacionada ao processo de reposição e planejamento, concentrados nas operações do varejo.

Com base nisso, o principal objetivo deste trabalho é analisar a viabilidade de aplicação uma sistemática de gestão de estoques desenvolvida em ambiente acadêmico a um caso real de permitindo o aumento da disponibilidade de produtos na loja através do equacionamento do seguinte sistema: minimizar os custos operacionais e de estoque (do varejo) tendo como restrição um nível mínimo de serviço ao cliente.

Este trabalho utilizará a relação comercial e logística entre varejo e indústria, através de reposição diária de múltiplos itens em local único, via pesquisa experimental entre duas empresas que representam os respectivos setores que, para fins de simplificação, serão neste trabalho identificadas como Indústria e Varejo.

\subsection{A INDÚSTRIA}

A Indústria é uma empresa multinacional de bens de consumo, com atuação em mais de 30 países líder em diversas categorias de produtos (o conceito de categoria será melhor explicado adiante).

A operação brasileira possui faturamento médio de $R \$ 1$ bilhão ao ano, atendendo em todo território nacional cerca de 600 clientes em 1.800 pontos de entrega, onde distribui cerca de 900 SKUs.

A sigla "SKU", acrônimo de Stock Keeping Unit é normalmente usada para designar o código de cada variante de um produto (ou menor unidade de venda). Tanto na Indústria quanto no Varejo tal sigla é largamente utilizada em todos os departamentos, e será recorrente no presente texto. 
Segundo Levy e Weitz (2000), uma categoria é um conjunto de itens que o cliente entende como substituíveis entre si.

Desta forma, a classificação dos produtos chamados de achocolatados, com suas diversas marcas, tipos e tamanhos, são expostos para comercialização em uma mesma gôndola ou prateleira, permitindo aos clientes compararem e definirem a melhor escolha do produto a ser adquirido.

Da mesma forma, os diversos tipos de detergentes ou condicionadores ou pães podem ser agrupados entre si, caracterizando categorias.

Este conceito é particularmente importante para a Indústria, sendo a base para a maneira como se gerenciam custos, formato de abastecimento e como se organizam estratégias de inovação em produtos.

É também fundamental para o Varejo na tomada de decisões relacionadas à quantidade de produtos diferentes com que cada loja deve trabalhar face às limitações de espaço e de dinheiro para investimento em estoques.

\subsubsection{A Missão da Indústria}

A Indústria tem como missão: "Tornar-se a maior companhia de bens de consumo nas categorias onde atua, contribuindo com soluções melhores e mais completas ao consumidor final".

Para a Indústria, o principal compromisso está em conhecer profundamente as necessidades do consumidor final, a fim de desenvolver os melhores produtos para atender (e em alguns casos superar) suas expectativas, garantindo assim que, após sua primeira experimentação, ele retorne para novas re-compras. 


\subsubsection{Canais de distribuição}

Como estratégia de distribuição, a Indústria utiliza os canais convencionais das demais indústrias de bens de consumo, com o objetivo de garantir sua distribuição em todo o território nacional, conforme descrito abaixo:

Tabela 1.1 - Composição e função dos canais de Distribuição da Indústria

\begin{tabular}{clc}
\hline Canal de Distribuição & \multicolumn{1}{c}{ Composição } & Função \\
\hline Varejo Direto & $\begin{array}{l}\text { Supermercados } \\
\text { Redes de Drogarias } \\
\text { Lojas de Departamento }\end{array}$ & $\begin{array}{c}\text { Visibilidade experimentação } \\
\text { através de amplo sortimento de } \\
\text { sku's }\end{array}$ \\
\hline Varejo Indireto & Distribuidores & $\begin{array}{c}\text { Visibilidade e experimentação } \\
\text { através de sortimento específico } \\
\text { de sku's }\end{array}$ \\
& $\begin{array}{l}\text { Atacados } \\
\text { Cash \& Carry }\end{array}$ & Distribuição numérica \\
\hline
\end{tabular}

O canal de varejo direto é representado em sua maioria pelos supermercados, redes de drogarias e grandes lojas de departamentos; é atendido diretamente pela equipe de vendas e de logística da Indústria.

Possui como principal função: garantir a visibilidade e experimentação de uma ampla faixa de sortimento de produtos. Este canal é considerado a vitrine de todos os novos lançamentos em diversas categorias e também um dos principais responsáveis pela construção e consolidação de suas marcas.

O canal de varejo indireto está dividido em distribuidores exclusivos agrupados por regiões geográficas com a finalidade de garantir a cobertura de varejos de médio porte (pequenos supermercados, farmácias independentes, lojas de conveniência etc.), localizados nos raios de ação de cada distribuidor. 
Sua principal função é atuar como uma extensão da Indústria, permitindo um sortimento mais específico a cada sub-canal, de forma a desenvolver os mesmos níveis de visibilidade e experimentação alinhados às estratégias de cada categoria, como se esses varejos fossem atendidos pela equipe de vendas própria da Indústria.

Os Atacados e Cash \& Carry (atacados que comercializam também ao consumidor final, além de varejos de pequeno porte) possuem atuação nacional, vendem produtos de diversas indústrias e possuem como clientes-foco o canal tradicional, varejos de pequeno porte (com até dez caixas de atendimento) em todos os segmentos.

Sua principal função é garantir a distribuição numérica (garantir presença física dos produtos em um número máximo de lojas atendidas por este canal) sem limitação geográfica para sua ação.

\subsubsection{Estratégia do negócio}

A Indústria possui uma desafiadora meta de crescimento, suportada por duas principais estratégias:

Aumento do portifólio de produtos: A indústria dobrará os número de categorias na qual atua através de uma agenda intensa de lançamentos de produtos ao longo dos próximos 24 meses.

Investimento em visibilidade e experimentação: para dar suporte à construção de suas novas marcas, a Indústria atuará fortemente com propaganda em diversas mídias (televisão, revistas especializadas, jornais etc.) e principalmente ações promocionais concentradas no canal de varejo direto. 


\subsection{O VAREJO}

O Varejo possui cerca de 100 lojas ao longo de 15 estados cobrindo praticamente todo território nacional. Com faturamento anual de $\mathrm{R} \$ 5$ bilhões, emprega cerca de 25 mil pessoas em sua operação incluindo lojas, escritórios e centros de distribuição, cerca de 4 ao todo, localizados nas regiões sudeste, nordeste e sul.

\subsubsection{Formatos das lojas}

A fim de atender aos diferentes perfis de consumidores que frequentam suas lojas, considerando a diversidade cultural, nível sócio-econômico entre outras necessidades, o Varejo atua com vários formatos de lojas, entre eles: Hiper, Super e lojas de vizinhança

Tabela 1.2 - Tamanho, quantidade de SKUs e foco dos formatos de loja

\begin{tabular}{cccc}
\hline Formato de Loja & Tamanho & Número de SKU's & Foco \\
\hline Hiper & 5.000 a $7.500 \mathrm{~m} 2$ & 55.000 & $\begin{array}{l}\text { Eletroeletrônicos, alimentos, perecíveis, } \\
\text { têxteis, utilidades domésticas, } \\
\text { brinquedos, papelaria, CDs e DVDs, } \\
\text { pets, produtos para limpeza e jardinagem }\end{array}$ \\
\hline Super & 1.200 a $4.900 \mathrm{~m} 2$ & 15.000 & Hortifruti, padaria, açougue e peixaria \\
\hline Loja de Vizinhança & 300 a $1.100 \mathrm{~m} 2$ & 4.500 & Alimentos e itens de higiene e limpeza \\
\hline
\end{tabular}

A principal proposta do formato Hiper é oferecer uma ampla variedade de itens nas mais diversas seções, de forma que o consumidor possa encontrar tudo o que procura em um só lugar, incluindo centros de serviços que funcionam dentro da própria loja - como revelação fotográfica, farmácia, artigos para presentes etc. 
Em geral, este formato está direcionado para o público das classe A e B. Algumas destas lojas atendem 24 horas por dia.

Com relação ao formato Super, sua especialização está nas seções de perecíveis, hortifruti, padaria, açougue e peixaria, além de uma linha com mais de 500 produtos de marcas exclusivas, que busca proporcionar aos consumidores uma boa relação entre custo e benefício, com foco nos públicos A e B.

O formato de Loja de vizinhança tem como proposta oferecer a conveniência de estar mais próximo de seus consumidores. Este formato opera com preços baixos e sortimento pequeno (cerca de $4.500 \mathrm{SKUs}$ ) com foco em produtos de primeira necessidade (alimentos, itens de higiene e limpeza) para públicos das classes C e D.

\subsubsection{Estratégia do negócio}

O Varejo baseia sua estratégia de crescimento em três principais pilares: aquisições de outras redes, abertura de novas lojas e aumento de volume de vendas nas lojas atuais, sendo este último o responsável pela maior parte do crescimento projetado anualmente.

Basicamente, o aumento de vendas em lojas segundo afirmação do Varejo é resultado direto das atividades promocionais (propaganda em televisão, tablóides, pontos extras, demonstradoras de produtos, promoções que envolvam brindes) e lançamentos de novos produtos. 


\section{DESCRIÇÃO DO PROBLEMA}

\subsection{A RUPTURA DE ESTOQUE}

O estudo entitulado "Retail Out-of-stocks: A Worldwide examination of extent, causes and consumer responses", patrocinado pela empresa Procter \& Gamble em associação com a Emory University, University of Colorado (EUA) e University of St. Gallen (Suiça), que cobriu 29 países e 71.000 consumidores em 661 lojas de varejos, trouxe algumas importantes contribuições para o meio acadêmico sobre o tema das rupturas de estoque, como poderá ser visto abaixo.

Segundo o resultados da pesquisa de Gruen, Corsten e Bharadwaj (2002), rupturas permanecem como um grande problema para varejos, distribuidores e indústrias no mundo dos bens de consumo.

Os avanços no gerenciamento da cadeia de suprimentos, como as iniciativas do Efficient Consumer Response (ECR), o gerenciamento de categorias e os investimentos em tecnologias de acompanhamento de inventário não têm reduzido o nível geral de rupturas nas gôndolas das lojas quando comparado ao que existia nos estudos anteriores.

As taxas de ruptura variam amplamente entre os varejos dependendo de uma série de fatores, porém a maioria tende a situar-se na faixa de $5 \%$ a $10 \%$, sendo que, para produtos promocionais ou de venda rápida, as taxas de ruptura regularmente excedem 10\%. A taxa média de ruptura mundial é estimada em $8,3 \%$.

A análise mostra ainda que de $70 \%$ a $75 \%$ das rupturas são resultado direto das práticas das lojas (ou subestimando a demanda ou apresentando processos e ciclos de pedidos muito extensos) e de práticas de reabastecimento das gôndolas (produto está na loja mas não na prateleira), como pode ser visto na figura 2.1. 


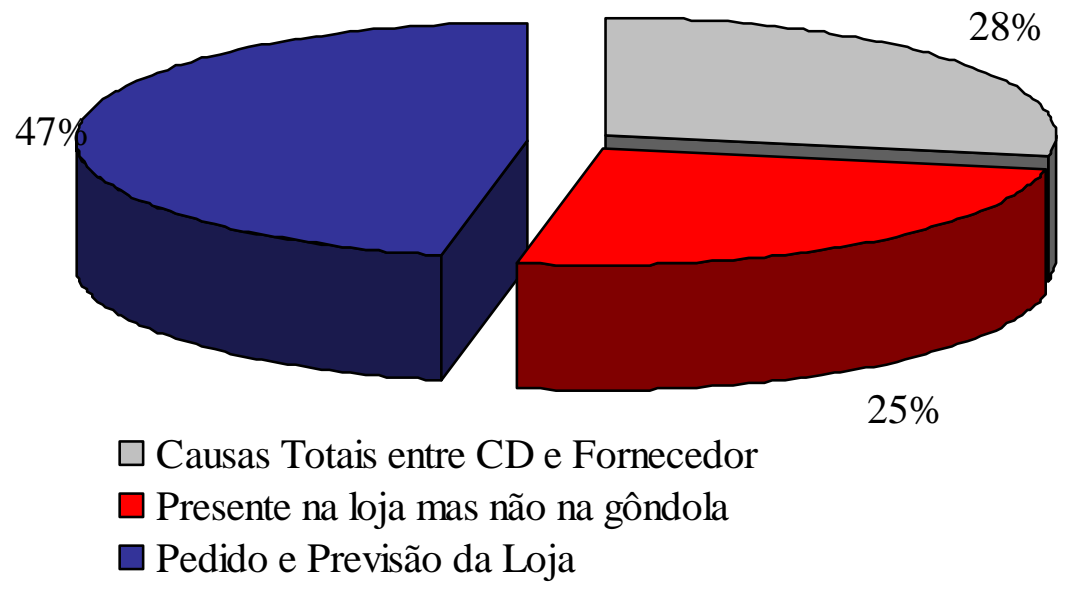

Figura 2.1 - Causas de rupturas: médias mundiais. Fonte: Gruen, Corsten e Bharadwaj (2002)

Com relação à reação do consumidor quando não encontra o produto na loja, como pode ser visto na figura 2.2, o varejo entre os demais elos da cadeia é quem mais perde em termos de intenção de compra.

Cerca de 55\% entre migração de consumidores para outras lojas, não compra ou postergação da compra; em segundo, a indústria com 35\% entre migração do consumidor para outras marcas ou não compra.

Ambos os resultados não incluem o impacto das substituições por mesma marca, que geralmente tendem a ser por produtos mais baratos (Gruen, Corsten e Bharadwaj, 2002). 


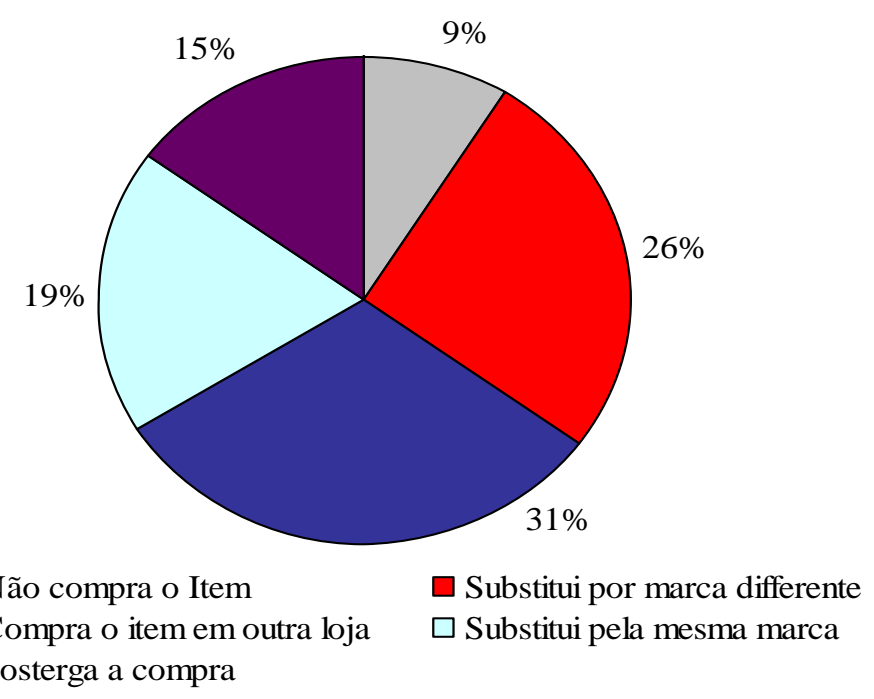

Figura 2.2 - Resposta mundial do consumidor às rupturas - média das oito maiores categorias.

Fonte: Gruen, Corsten e Bharadwaj (2002)

Pesquisa semelhante desenvolvida no Brasil em 2004 pela ACNielsen com colaboração do ECR-Brasil (Efficient Consumer Response) e da Associação Brasileira de Supermercados (ABRAS) analisou o comportamento dos consumidores perante a falta de produtos na gôndola.

Os resultados apresentados podem ser vistos na figura 2.3.

Os resultados do estudo brasileiro (ACNielsen, 2004) mostraram que no Brasil a tendência é inversa em termos de perda entre indústria e varejo, e ainda mais significativa do que o estudo conduzido por Gruen, Corsten e Bharadwaj (2002).

No que diz respeito à reação do consumidor diante da ruptura de produtos na gôndola por categoria, a indústria perde em intenção de compra de $48 \%$ a $71 \%$ enquanto o varejo é impactado pelo mesmo problema entre $44 \%$ e $58 \%$. 
Produtos de higiene pessoal Bebidas em Geral Chocolate Café Margarina Iogurtes Produtos de Limpeza Bolachas e Biscoitos Macarrão / Massas Óleo de Cozinha Média

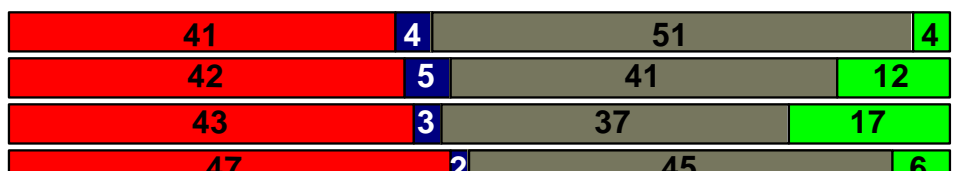

\begin{tabular}{|c|cc|c|}
\hline \hline 47 & 2 & 45 & \multicolumn{2}{|c|}{17} \\
\hline \hline 48 & 1 & 43 & 8 \\
\hline
\end{tabular}

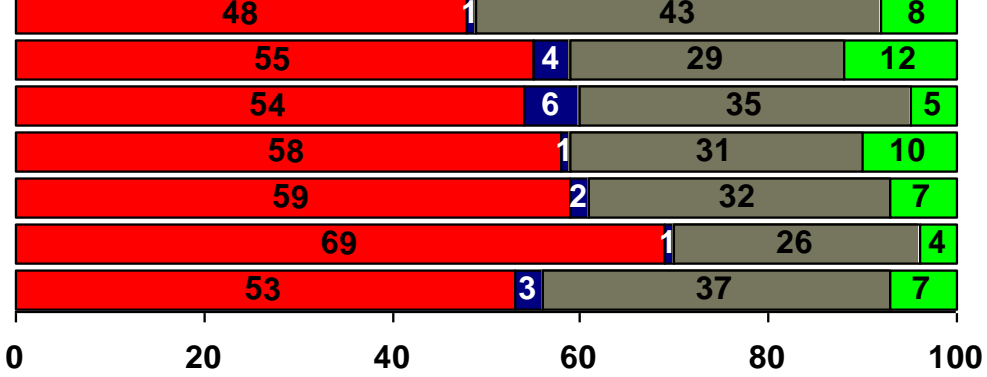

- Substitui por marca diferente

- Substitui pela mesma marca

$\square$ Compra o item em outra loja

$\square$ Desiste de comprar o item

Figura 2-3 - Reação do consumidor brasileiro diante da ruptura do produto Fonte: AC Nielsen (2004)

Segundo este mesmo estudo (ACNielsen, 2004), a perda estimada foi de que cada $1 \%$ de ruptura equivaleria a uma perda monetária direta de cerca de US\$ 1 milhão para toda a cadeia - produção, distribuição e varejo.

Não estão aí incluídos os impactos indiretos nas marcas em termos de perda de fidelização e imagem, queda de margens de vendas e fluxo de caixa para ambos os atores no caso de substituição por produto mais barato ou postergação de compra (indústria e varejo).

\subsubsection{O impacto da ruptura de estoque no varejo}

Indústria e Varejo acordaram um método comum para mensurar as rupturas em gôndola, método este já utilizado pela Indústria em outras empresas de varejo por ele atendidas.

Tal método consiste na contratação de empresa especializada (provedor) na coleta de informações, que, ao longo de cada semana, efetua visitas às lojas mais significativas da rede de lojas do Varejo (80/20 do faturamento total) para coletar 
informações de presença em gôndola de uma lista de SKUs pré-estabelecidos entre Indústria e Varejo.

As informações de rupturas numéricas por SKU e por loja são então ponderadas pela empresa especializada de acordo com o peso das vendas em quantidade vendida de cada SKU em cada loja, para finalmente gerar o número de rupturas ponderado por SKU e loja e, assim, todos os níveis de consolidação acima (região, categoria, total categoria, semanal e mensal).

A figura 2.4 mostra os resultados das rupturas em \% num período de 12 meses do Varejo, medidos através do mesmo método e mesmo provedor.

Como se pode concluir, os resultados de ruptura mensal do Varejo estão em linha com a média dos demais varejos conforme comparação com os números divulgados pela pesquisa de Gruen, Corsten e Bharadwaj (2002).

Segundo informações recebidas pelos responsáveis pela área comercial e logística do Varejo, esta situação é descrita como absolutamente crítica e um dos mais importantes problemas enfrentados por eles e pelos demais do setor.

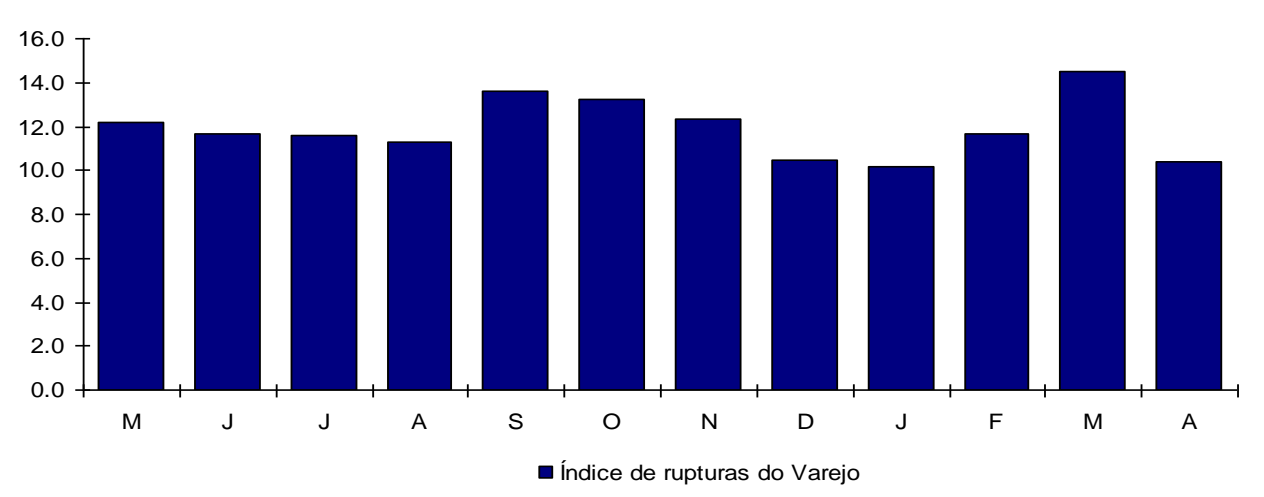

Figura 2-4 - Resultado das rupturas dos itens em gôndola em \% no Varejo em período de 12 meses 


\subsection{PROCESSO DE ABASTECIMENTO DO VAREJO}

\subsubsection{Os atores: papéis e responsabilidades}

Tanto Varejo quanto Indústria contam com equipes para desempenharem papéis específicos em suas organizações no ciclo do pedido. Segue abaixo detalhamento das responsabilidades dos principais atores deste processo.

\subsubsection{Equipe da Indústria}

Analista de suprimentos - coordena com as plantas as quantidades de cada SKU por categoria que precisam ser produzidos dentro do mês. Executa uma previsão de demanda.

Analista de serviço ao cliente - valida o pedido do cliente, identifica erros e soluciona problemas no tempo de faturamento do pedido, incluindo disponibilidade de produto, correção de cadastro, prazos de pagamento etc.

Supervisor de serviço ao cliente - é responsável pelo atendimento e acompanhamento do nível de serviço do cliente, responde pelos principais Key Performance Indicators (KPl's) estabelecidos entre Indústria e Varejo. Também é responsável pela gestão de estoques e rupturas no Varejo.

Vendedor - executa os planos pré-determinados por categoria. É responsável pelas negociações de atividades promocionais, planos de lançamentos e toda atividade de geração de demanda em loja. 
Promotor de vendas - é responsável pelo abastecimento de loja e execução das atividades promocionais desenvolvidos pelo vendedor (pontos extras de exposição de produtos, colocação de material promocional na loja etc.).

\subsubsection{Equipe do Varejo}

Gerente de categoria - é responsável pelo gerenciamento de categorias específicas, a fim de garantir os objetivos de margem, volume em vendas e melhor aproveitamento (lucratividade) por metro quadrado nas lojas. É o interlocutor direto do vendedor da Indústria.

Supervisor de abastecimento do CD - é o responsável pela manutenção do sistema de reabastecimento do CD (Centro de Distribuição) e da gestão dos estoques no CD. Também responde pela aprovação e cumprimento do pedido solicitado pelo gerente de categoria à Indústria.

Coordenador de abastecimento da loja - é responsável pela manutenção do sistema de reabastecimento dos SKUs de uma determinada loja e da gestão dos estoques da loja.

\subsubsection{Ciclo do pedido}

Com a finalidade de detalhar o fluxo completo da cadeia de suprimentos entre a Indústria e o Varejo, foi elaborado um fluxograma, que pode ser visto com detalhes na figura 2.5 .

A abrangência do processo estudado compreende desde a loja (através da geração e envio do pedido), passando pelas sucessivas etapas dentro da estrutura do Varejo 
e da Indústria, até a entrega das mercadorias do pedido na própria loja como última etapa.

O fluxo está dividido em duas partes: Pedidos automáticos, gerados através do sistema de reabastecimento do Varejo e pedidos promocionais, gerados manualmente através da apresentação e negociação do plano de vendas entre o vendedor e o comprador (chamado de gerente da categoria) do Varejo.

Ambos os tipos de pedidos são transmitidos eletronicamente através de um provedor de Eletronic Data Interchange (EDI) e são entregues para as lojas através da sistemática de Cross-Docking.

Cross-Docking é um termo em inglês que designa uma operação na qual não há armazenamento do produto no Centro de Distribuição (CD) do varejo, permitindo que a manipulação e distribuição dos pedidos sejam feitas para as lojas no mesmo dia de recebimento no CD, ou seja apenas "cruzando as docas". 


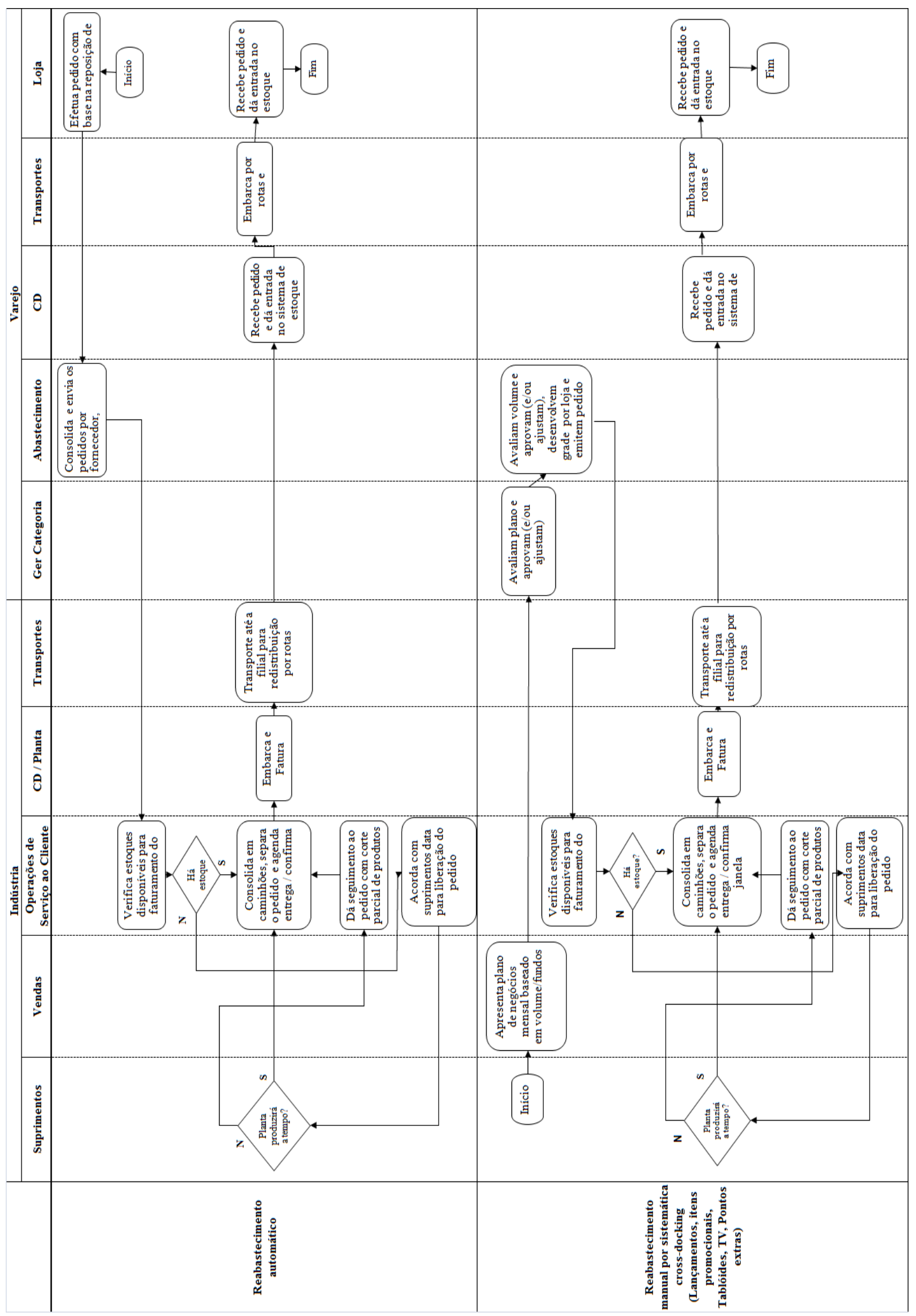

Figura 2.5 - Ciclo do Pedido de SKUs regulares e atividades promocionais 


\subsubsection{As causas-raízes da ruptura de estoque}

A fim de mapear as causas-raízes da ruptura de estoque, foram selecionadas dez lojas da rede do Varejo e $30 \mathrm{SKUs}$ entre as principais categorias da Indústria. Uma equipe multidisciplinar da Indústria, entre analistas de serviço ao cliente e vendedores, efetuaram a coleta das informações de presença dos SKUs nas lojas selecionadas.

Como período, foram escolhidas as primeiras duas semanas do mês, por se tratar das de maior volume de vendas pela loja em relação às semanas posteriores, segundo informação do Varejo.

Para auxiliar esta equipe na identificação das causas-raízes, foi elaborado o fluxograma da figura 2.6, com a finalidade de guiar e padronizar a forma de investigação das causas de rupturas através de um roteiro pré-acordado entre Indústria e Varejo.

Não foram adicionadas todas as possibilidades em termos de causas, uma vez que a intenção deste trabalho era identificar as causas-raízes mais relevantes.

A coleta das informações foi efetuada no momento da visita à loja, sem aviso prévio, iniciando o processo de investigação de presença física do produto, visualmente na própria gôndola da loja.

Foi considerada como ruptura a ausência do produto na gôndola, não importando se este estava presente em qualquer outro equipamento da loja (pontos extras de exposição de produtos, caixas de atendimento e pagamento etc.).

Para as informações não presentes na loja, como existência ou não de pedido da loja, pedido em trânsito, estoque no $\mathrm{CD}$ etc., estas eram informadas pelo coordenador de abastecimento da loja no momento da visita. 


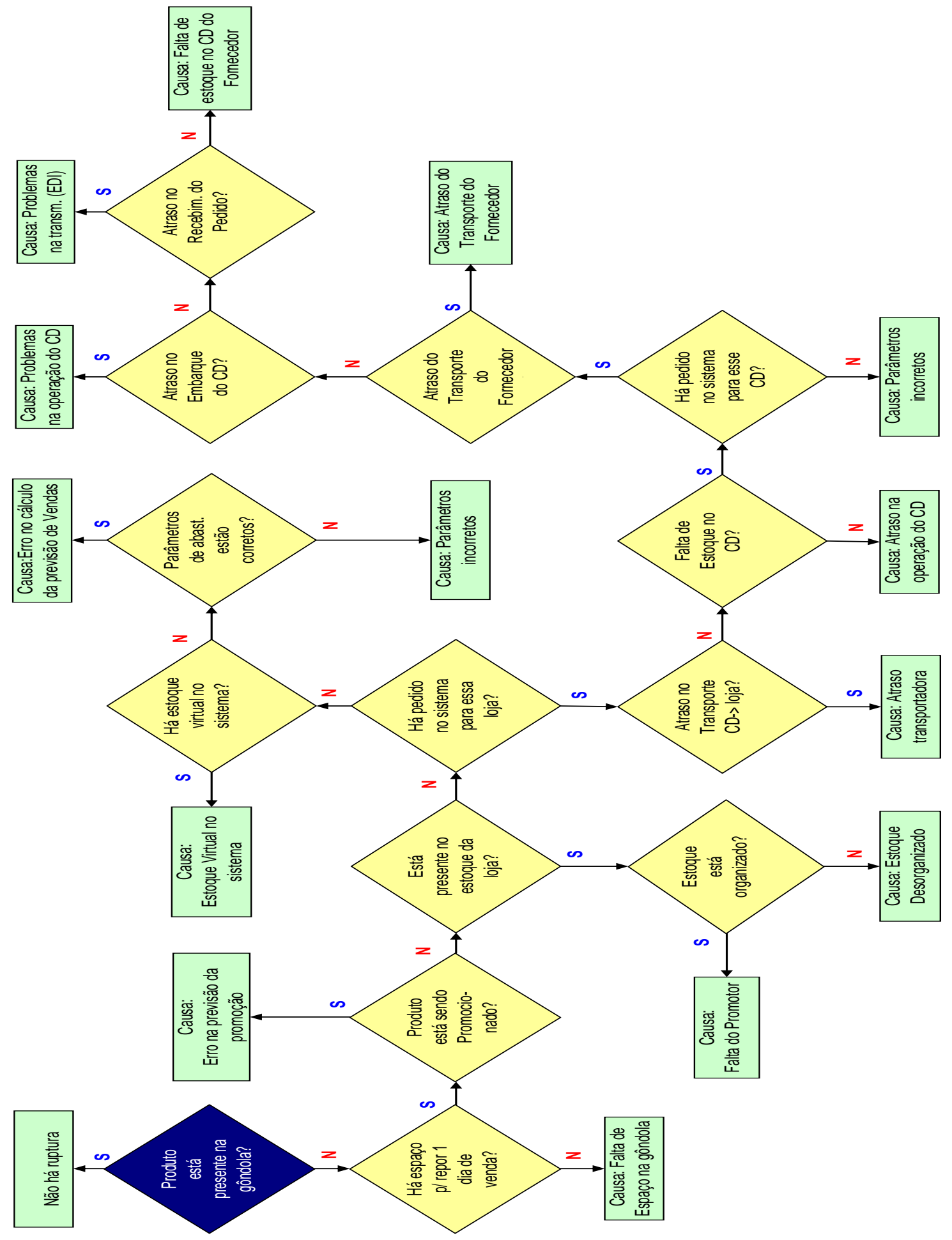

Figura 2.6 - Fluxograma para identificação das causas-raízes de ruptura na gôndola 
Após o término do levantamento, os dados foram consolidados por causas-raízes, agrupados por área do ciclo do pedido, como pode ser visto na tabela 2.1.

Através deste estudo preliminar, pode-se concluir que os erros de previsão de demanda na loja foram responsáveis por $46 \%$ das rupturas identificadas na amostra, sendo esta a causa mais significativa entre todas as demais, seguida de erro no planejamento das promoções e lançamentos (15\%) e parâmetros incorretos no abastecimento de loja (7\%).

Juntos, os três respondem por $68 \%$ das causas totais de rupturas, conforme a amostra e roteiro utilizados.

Tais resultados confirmam os dados obtidos do estudo de Gruen, Corsten e Bharadwaj (2002), que identificaram como causa das rupturas problemas em pedidos e previsão de demanda como os mais significativos entre os demais (47\%).

\section{Tabela 2.1 - Representatividade das causas-raízes das rupturas por área no ciclo do pedido}

\begin{tabular}{|llc|}
\hline \multicolumn{1}{c}{ Área } & \multicolumn{1}{c}{ Causa de Ruptura } & \% Representatividade \\
\hline Suprimentos & Falta de produto no CD - Fornecedor & $4,1 \%$ \\
\hline Operações de Serviço ao Cliente & EDI não funciona (interrupção de envio de pedidos) & $1,5 \%$ \\
\hline CD/Planta & Atraso na operação do CD - Fornecedor & $2,6 \%$ \\
\hline Transportes & Atraso de entrega Transportadora Fornecedor & $5,5 \%$ \\
\hline Abastecimento & Erro de planejamento nas promoções e lançamentos & $15,0 \%$ \\
\hline \multirow{3}{*}{ CD } & Parâmetros incorretos de abastecimento do CD & $1,0 \%$ \\
\hline Tranportes & Atraso na operação do CD - Cliente & $1,5 \%$ \\
\hline Loja & Atraso de entrega CD Cliente => Loja & $2,7 \%$ \\
\hline & Falta de Abastecedor & $4,3 \%$ \\
\cline { 2 - 3 } & Estoque desorganizado & $4,2 \%$ \\
\cline { 2 - 3 } & Falta de Espaço em Gôndola & $1,6 \%$ \\
\cline { 2 - 3 } & Erro na previsão de venda & $46,0 \%$ \\
\cline { 2 - 3 } & Parâmetros incorretos de abastecimento da loja & $7,0 \%$ \\
\cline { 2 - 3 } & Estoque Virtual na Loja & $3,2 \%$ \\
\hline
\end{tabular}




\subsection{O PROBLEMA}

O estudo quantitativo efetuado através da coleta das informações de rupturas na amostra de lojas do Varejo com relação à amostra pré-selecionada de SKUs da Indústria permitiu identificar e quantificar as principais causas de rupturas, com destaque para a mais significativa delas: erro na previsão de demanda da loja (46\%).

A previsão de demanda na loja é feita através dos parâmetros de abastecimento de estoque e modelos de previsão definidos pelo coordenador de abastecimento da loja (ou eventualmente o supervisor de abastecimento do CD).

Em geral, as mesmas regras de reposição são aplicadas para a maior parte do SKUs, visto que é humanamente impossível para a equipe do Varejo - em geral, um e, no máximo, dois abastecedores por loja - gerenciar no detalhe um sortimento de cerca de 55.000 SKUs, caso de uma loja de formato Hiper.

Outro ponto importante a ser destacado é o trade-off natural que este abastecedor enfrenta nas suas decisões do dia-a-dia.

Se, por um lado, ele é responsável por garantir que não falte produtos nas gôndolas em quantidade suficiente para evitar a geração de rupturas (o que hoje é uma prioridade para o Varejo), por outro, ele possui como meta a redução dos estoques em loja, que compõem os objetivos de redução de custo determinados pela gerência do Varejo.

Outro destaque para a composição da situação-problema é a formação técnica destes abastecedores.

Em geral são funcionários da equipe de loja que efetuam rodízio através das funções, apresentando baixa preparação técnica do ponto de vista de entendimento dos modelos matemáticos de previsão ou de gestão de estoques, limitando-se a manipular o sistema existente de forma empírica ou simplesmente repetindo decisões tomadas por antecessores na mesma função. 


\subsection{O OBJETIVO DO TRABALHO}

O objetivo desse trabalho é analisar a viabilidade de aplicação de uma sistemática de gestão de estoques que permita escolher e parametrizar modelos de decisão de reposição de itens para ser usado pelo analista de serviço ao cliente junto aos coordenadores de abastecimento das lojas.

O intuito é auxiliá-los na redução dos desvios de previsão de demanda e parametrização adequada do sistema de abastecimento do Varejo para suportar a consequente geração de pedido.

Trata-se de uma pesquisa experimental apoiada em um modelo aplicado a duas empresas que representam ambos os setores (varejo e indústria) por sua similaridade em métodos de operações logísticas e comerciais, aqui identificadas por Indústria e Varejo.

Este modelo irá se concentrar em identificar a correta parametrização que otimize conjuntamente os custos operacionais de ruptura, armazenagem e aquisição.

Com isso, o objetivo do modelo proposto pode ser mais bem especificado como:

Minimizar os custos operacionais e de estoque (do Varejo) tendo como restrição um nível mínimo de serviço ao cliente.

\subsection{RELEVÂNCIA}

Acredita-se que o presente trabalho poderá ter relevância significativa para varejos e indústrias envolvidas na cadeia de abastecimento.

Para todo o setor da indústria, a utilização de um modelo de decisão de estoques que apoie a redução de rupturas nas gôndolas trará, além de aumento no volume de 
vendas, impactos positivos na construção e posicionamento de suas marcas atuais e futuras, reduzindo os riscos de experimentação dos concorrentes pelos consumidores.

Para o setor do varejo, além do aumento de volume em vendas e na fidelização do consumidor à loja, é esperado que haja, ainda, redução em seus estoques (embora não seja impossível antever o quanto).

O modelo servirá também de guia para a reprodução de seus parâmetros e modelos de previsão em seu sistema de abastecimento, ampliando a capacidade técnica de sua equipe de loja.

Por fim, para ambos os setores, contarem com uma ferramenta que reduza significativamente o risco de rupturas e aumente o nível de colaboração e visibilidade através da cadeia varejo-indústria poderá contribuir para o cumprimento de seus desafiadores compromissos de crescimento - e de forma robusta e sustentável para os anos vindouros. 


\section{REVISÃO BIBLIOGRÁFICA - PREVISÃO DE DEMANDA}

O modelo de decisão, objetivo deste trabalho, será desenvolvido com base em modelos de gestão de estoques, que serão mais bem detalhados no capitulo 4. Tais modelos classificam-se por reativos e ativos.

Considerando que este último utiliza previsão de demanda como uma de suas entradas, a revisão bibliográfica iniciará abordando este assunto.

\subsection{DEFINIÇÃO E PROPÓSITO}

O processo da previsão, cujas muitas técnicas usadas hoje foram desenvolvidas no século XIX, envolve o estudo de dados históricos para descobrir tendências e padrões. Este conhecimento é usado para projetar dados em períodos de tempo no futuro como previsões (...).

Como o mundo dos negócios tem se tornado mais complexo, a necessidade de acessar o futuro numa base racional tem crescido, e a previsão tem assumido uma posição proeminente no processo de administração de negócios. Hanke e Reitsch (1998).

Segundo Hanke e Reitsch (1998), o propósito da previsão é reduzir a faixa de incerteza dentro da qual podem ser gerenciados julgamentos. Este propósito sugere duas regras primárias nas quais o processo de previsão deve aderir:

1. A previsão deve ser tecnicamente correta e produzir previsões precisas o suficiente para atender às necessidades das empresas.

2. O procedimento de previsão e seus resultados devem ser efetivamente apresentados para gerenciamento, uma vez que as previsões são utilizadas 
no processo de tomada de decisão para uma vantagem da empresa; resultados devem também ser justificados numa base de custo-benefício.

Com relação a quem necessita fazer previsões, Hanke e Reitsch (1998) afirmam que quase toda organização, grande ou pequena, privada ou pública, usa previsões explicitamente ou implicitamente uma vez que quase toda organização deve planejar para alcançar condições do futuro para o qual tem conhecimento imperfeito.

Os autores consideram as seguintes questões, que sugerem a necessidade de algum procedimento de previsão:

- Se crescermos nosso orçamento de propaganda em $10 \%$, como as vendas serão afetadas?

- Quanto lucro o governo do estado deve esperar nos próximos dois anos?

- Quantas unidades devem ser vendidas no esforço de recuperar o investimento feito em equipamentos de produção?

- Que fatores podemos identificar que irão explicar a variabilidade nas vendas unitárias mensais?

- Qual é a previsão ano-a-ano para o balanço de empréstimos totais de nosso banco para os próximos dez anos?

- Haverá uma recessão? Se sim, quando começará? Quão severa será, e quando irá terminar?

De uma forma geral, as etapas da previsão podem ser vistas através da figura 3.1: 


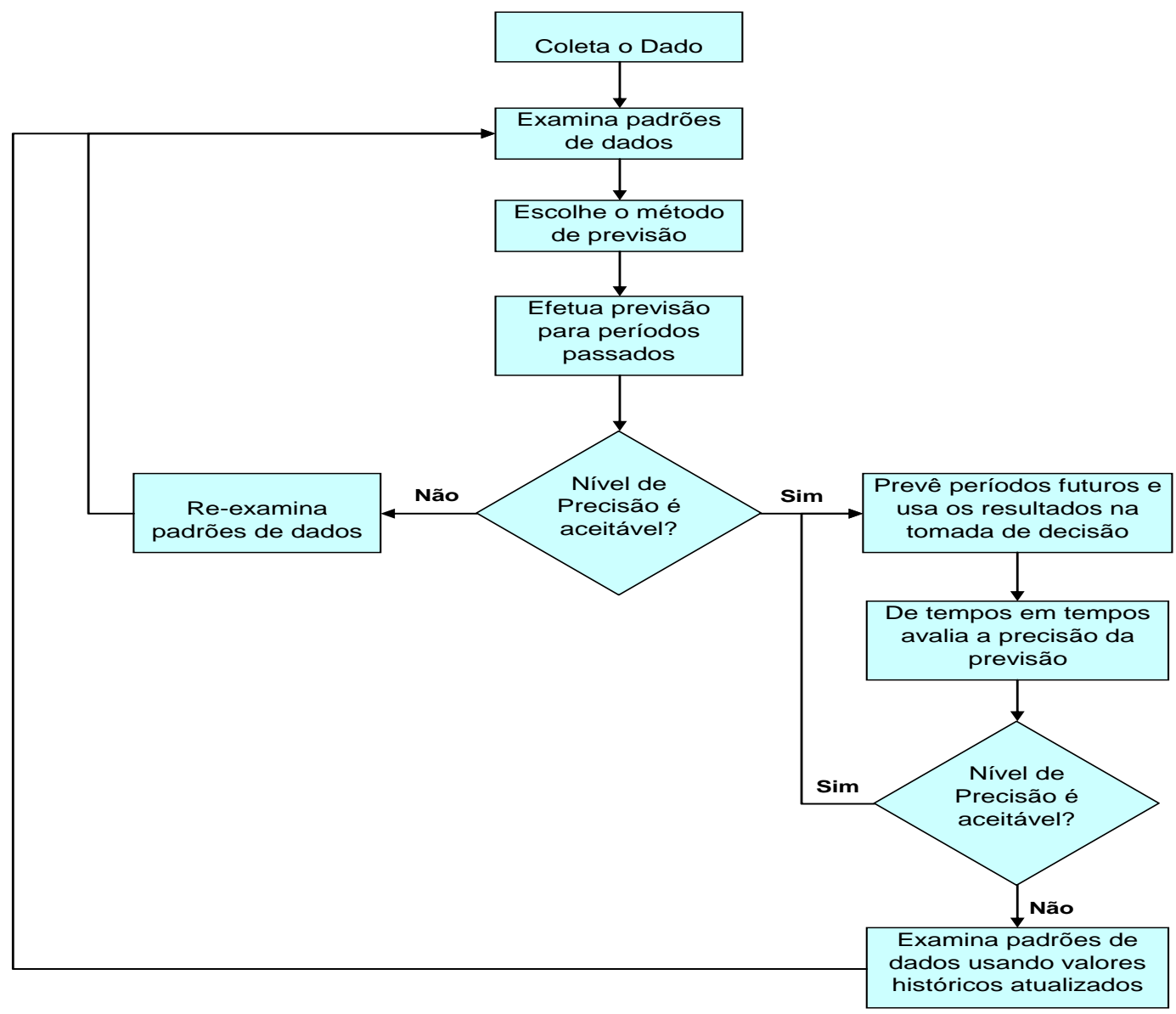

Figura 3.1 - O processo de previsão. Fonte: Hanke e Reitsch (1998)

\subsection{MÉTODOS DE PREVISÃO}

Os métodos, também chamados de técnicas de previsão, basicamente dividem-se em dois: qualitativos e quantitativos.

Os métodos de previsão qualitativos são baseadas no julgamento humano e em sua intuição mais do que na manipulação de dados históricos. São exemplos destas técnicas: Método Delphi, curva de crescimento, desenvolvimento de cenários, pesquisa de mercado e "focus groups".

Os métodos de previsão quantitativos são usados quando há suficientes dados históricos e quando estes dados são tidos como representativos de um futuro desconhecido. Segundo Hanke e Reitsch (1998), este julgamento é um passo 
importante no processo de previsão, uma vez que todas as técnicas quantitativas têm como premissa que o passado pode ser estendido ao futuro, de uma maneira que faça sentido prover previsões precisas.

\subsubsection{Classificação dos métodos de previsão}

Os métodos quantitativos podem ser classificadas em estatísticos e causais. Os métodos estatísticos concentram-se em padrões, suas alterações e influências aleatórias.

Os principais exemplos de técnicas estatísticas são: médias simples e móveis, suavização exponencial simples (modelo de Brown), com tendência (modelo de Holt), com tendência e sazonalidade (modelo de Holt Winter's), decomposição clássica - que serão detalhadas nas próximas seções - e metodologia Box-Jenkins.

Esta última assume que os dados não são representados separadamente pelos componentes de tendência, ciclicidade e sazonalidade, ao contrário dos demais modelos estatísticos (Hanke \& Reitsch, 1998).

Os métodos causais utilizam como premissa básica a de que o nível da variável de previsão é derivado do nível de outras variáveis relacionadas. Por exemplo, se o serviço ao cliente tem um efeito positivo sobre as vendas, conhecendo o nível de serviço ao cliente é possível projetar o nível de vendas.

Tais técnicas incluem regressões e múltiplas regressões, modelos econométricos, pesquisas de antecipação, modelos de entrada e saída entre outros (Ballou, 2006).

É importante ressaltar que os modelos de séries temporais podem apresentar resultados superiores aos demais modelos, pois a complexidade nos modelos de previsão não aumenta necessariamente sua precisão (Makridakis e Wheelright, 1978). 


\subsubsection{Fatores de escolha do método de previsão}

Segundo Hanke e Reitsch (1998), para selecionar o método apropriado, o planejador deve estar apto a cumprir os seguintes passos:

- Definir a natureza do problema de previsão

- Explicar a natureza dos dados sob investigação

- Descrever as capacitações e limitações das potencialmente úteis técnicas de previsão

- Desenvolver algum critério pré-determinado no qual a escolha da decisão possa ser feita

O maior fator de influência da seleção do método de previsão é a identificação e entendimento dos padrões históricos dos dados. Se apresentam tendência, ciclicidade ou sazonalidade, as técnicas que são capazes de prever usando estes padrões devem ser selecionadas.

\subsubsection{Padrões de demanda}

Como já parcialmente introduzido nas seções anteriores, os principais padrões de demanda podem ser definidos conforme abaixo (Hanke e Reitsch, 1998):

- Tendência: é um componente de longo prazo que representa o crescimento ou declínio numa séria temporal durante um período estendido de tempo

- Ciclicidade: é um componente que causa flutuações cíclicas ao longo de uma curva de tendência

- Sazonalidade: é um padrão de mudança que se repete período após período.

- Irregularidade: é um componente que mede a variabilidade da série temporal; uma vez que os demais componentes foram removidos, algumas vezes o componente irregular é chamado de variabilidade aleatória. 
Os métodos de projeção estão diretamente relacionados ao tipo de padrão dos dados (curvas) de uma série temporal, uma vez que o desenho de suas equações foi desenvolvido para lidar com cada um dos componentes acima de uma particular maneira.

A tabela 3.1 resume as curvas versus os métodos, foco deste trabalho. Tais métodos de previsão de demanda serão mais bem detalhados na seção 3.2.5.

Tabela 3-1 - Padrão da série histórica $x$ técnica de previsão.

\begin{tabular}{cc}
\hline Padrão da série histórica & Técnica de Previsão \\
\hline Constante & Métodos naïve, Médias (Simples, móvel), suavização exponencial simples e Box- \\
Jenkins
\end{tabular}

Fonte: Hanke e Reitsch (1998)

\subsubsection{Definição de autocorrelação}

É a correlação entre a variável defasada de um ou mais períodos e ela mesma (Hanke e Reitsch, 1998).

Para sistematizar tal análise, é utilizada uma ferramenta chamada autocorrelograma, que demonstra graficamente o resultado dos coeficientes de autocorrelação $\left(r_{k}\right)$ ao longo do número de defasagens utilizadas em cada análise.

Esta ferramenta é utilizada para identificar na série avaliada, se há tendência, sazonalidade ou aleatoriedade. Segundo Hanke e Reitsch (1998): 


$$
r_{k}=\frac{\sum_{t=k+1}^{n}\left(Y_{t}-\bar{Y}\right)\left(Y_{t-k}-\bar{Y}\right)}{\sum_{t=1}^{n}\left(Y_{t}-\bar{Y}\right)^{2}}
$$

Onde:

$r_{k}=$ coeficiente de autocorrelação para $\mathrm{k}$ períodos de defasagem

$\bar{Y}=$ média simples dos valores da série

$Y_{t}=$ observação do dado no período $\mathrm{t}$

$Y_{t-k}=$ observação do dado k períodos antes ou no período $\mathrm{t}-\mathrm{k}$

Segundo Hanke e Reitsch (1998), "se a série é verdadeiramente aleatória, quase todos os coeficientes de autocorrelação da amostra devem permanecer dentro da faixa entre zero e mais ou menos um certo número de erros".

Num específico nível de confiança, a série pode ser considerada aleatória se os coeficientes de autocorrelação estão dentro do intervalo produzido pela expressão [0 $+/-\mathrm{t} \times \mathrm{SEr}(\mathrm{k})]$.

A fórmula utilizada para calcular erros padrão, utilizada pelo programa de computador Minitab $®$ pode ser vista abaixo:

$$
\operatorname{SEr}(k)=\sqrt{\frac{1+2 \sum_{i=0}^{k-1}\left(r_{i}\right)^{2}}{n}}
$$

Onde:

$\operatorname{SEr}(k)=$ erro padrão da autocorrelação na defasagem $\mathrm{k}$

$r_{i}=$ autocorrelação na defasagem $\mathrm{k}$

$n=$ número de observações na série de dados

Para apoiar esta pesquisa, a ferramenta de autocorrelação foi utilizada para testar as 50 séries de combinações entre SKU e loja. Os resultados poderão ser vistos mais adiante na seção 4.3 em Análise de padrões de dados. 


\subsubsection{Métodos de previsão de demanda}

Métodos de previsão de demanda em aplicações de negócios incluem aqueles baseados em técnicas de regressão e Box Jenkins. Estes modelos, porém, são mais complicados e difíceis de implementar (Rajopadhye et al, 2001).

Para apoiar o desenvolvimento do modelo proposto, foram utilizados os seguintes métodos: métodos baseados em médias, desenvolvidos a partir de médias de observações ponderadas e métodos de suavização, que são baseados na média de valores passados de uma série de forma exponencial.

O detalhamento de tais modelos segundo Hanke e Reitsch (1998) pode ser visto abaixo:

\subsubsection{Métodos baseados em médias}

Segundo Hanke e Reitsch (1998), frequentemente gerentes enfrentam a situação em que previsões precisam ser atualizadas diariamente, semanalmente ou mensalmente para inventários contendo centenas ou milhares de itens.

Não sendo possível desenvolver sofisticadas técnicas de previsão para cada item, é necessária uma técnica de curto prazo que seja, rápida, barata e bastante simples. Neste contexto se encaixam os métodos baseados em média e suavização.

Tal situação (preferência dos gestores por modelos mais simples, baratos e rápidos) foi comprovada através de pesquisa sobre os principais métodos de previsão utilizados pelos gerentes.

Segundo Sanders (1997), as técnicas baseadas em médias e suavização foram os modelos quantitativos mais utilizados por gestores para tomada de decisão em previsão de venda, como pode ser visto na tabela abaixo: 
Tabela 3.2- Percentual de gerentes de manufatura que reportaram uso de técnicas de previsão de demanda

\begin{tabular}{ccccc}
\hline Técnica de Previsão & \multicolumn{4}{c}{ Frequência de uso (\%) } \\
Algumas vezes & Regularmente \\
\hline Método de Julgamento & n & Nunca & & 62.8 \\
Opinião do Gerente & & & 29.7 & 61.2 \\
Juri de opiniões de executivos & 84 & 7.5 & 30.6 & 58.3 \\
Composto da Força de vendas & 72 & 8.2 & 19.4 & 30.1 \\
\hline Métodos Quantitativos & & & & 39.5 \\
Modelo "Naïve" & 62 & 4.6 & 65.3 & 32.8 \\
Médias móveis & 80 & 18.2 & 42.3 & 14 \\
Suavização exponencial & 64 & 48.6 & 18.6 & 13.4 \\
Projeção "Straight line" & 58 & 51.8 & 34.2 & 2.5 \\
Regressão & 68 & 68.9 & 17.7 & 15.1 \\
Simulação & 40 & 73.5 & 24 & 13.5 \\
Decomposição & 41 & 71.4 & & \\
\hline
\end{tabular}

Fonte: Sanders (1997)

Dentre os principais tipos de métodos baseados em médias, seguem abaixo os mais revisitados na literatura, dos quais podemos destacar: média simples, média móvel, média móvel dupla.

\subsubsection{Métodos baseados em suavização}

Suavização é um procedimento para revisão contínua de uma estimativa à luz das mais recentes experiências. Este método é baseado nas médias (suavização) dos valores passados de uma série de uma maneira exponencial. As observações são ponderadas com o maior peso sendo dado às mais recentes observações.

Segundo Hanke e Reitsch (1998), podemos destacar os seguintes métodos de suavização: suavização exponencial, dupla suavização exponencial (método de Brown), suavização exponencial ajustada para tendência ou método de Holt e suavização exponencial ajustada para tendência e sazonalidade ou método de HoltWinter.

Segundo Holt (2004), os coeficientes de ponderação exponencial podem ser ajustados independentemente, de acordo com: a variabilidade aleatória de uma 
forma ou de outra, a velocidade com a qual a taxa de venda muda da tendência, a velocidade com a qual o padrão de sazonalidade muda e a velocidade com a qual a tendência muda respectivamente.

O uso da ponderação exponencial em médias móveis (suavização exponencial) para previsões não é limitado aos ajustes de taxa de tendência e sazonalidade. Tendências podem mudar por incrementos constantes ao invés de percentuais constantes; e flutuações sazonais podem ser aditivas ao invés de multiplicativas.

Neste mesmo trabalho, baseado numa análise exploratória, o autor destaca a grande flexibilidade dos métodos de suavização exponencial para previsões sazonais e com tendência.

Lewis (1997) destaca a suavização exponencial simples como o modelo ideal de previsão para curto prazo em sistemas de controles de inventário quando a demanda é estacionária.

Isso graças às suas vantagens de economia em termos de armazenamento de dados, fácil de ser implementada para novos produtos e geralmente bastante robusta.

No entanto, este modelo apresenta limitações para previsões de séries que apresentem característica de crescimento.

O trabalho de Snyder (2002) discutiu sobre métodos de previsão para inventários de rápida e de lenta movimentação através de uma melhoria na abordagem de Croston (Croston, 1972), modelo este desenvolvido para abordar demandas intermitentes.

Rajopadhye et al (2001) alcançaram interessantes resultados aplicando o método de Holt-Winters para previsão de ocupação de quartos de hotel.

Segundo os autores, embora tenham conseguido um bom nível de previsão para curtíssimo prazo, houve ocasiões em que 0 algorítmo não funcionou satisfatoriamente, pois este baseava-se apenas na previsão quantitativa. 
Isso os motivou a considerar o conhecimento humano ao processo, possibilitando a redução de erros de previsão.

DeLurgio (2009) avaliou 42 métodos entre diversos tipos de médias, suavização exponencial, Holt, Winter, ARIMA, entre outros, para determinação de demanda de pacientes em um ambulatório de um grande centro médico.

Sua pesquisa concluiu que os melhores resultados em termos de precisão da previsão vieram não da utilização de um ou outro tipo específico, mas sim da combinação entre eles (métodos baseados em regressão e métodos univariados os demais).

Borges (2003) também utilizou uma combinação de métodos de previsão para a construção de um modelo de previsão de demanda de água para um sistema adutor metropolitano.

Seu foco foi a série de Fourier combinada à média móvel, que, embora no geral tenha apresentando resultado satisfatório na programação diária da operação, sofreu viéses provenientes da qualidade inadequada dos dados e da falta de um fator de correção aplicado às médias móveis para reduzir influências sazonais.

Com base na bibliografia analisada, optou-se por utilizar os métodos de suavização exponencial como base para as previsões a serem feitas pelo modelo proposto neste trabalho, devido à sua ampla utilização e eficiência nas mais diferentes aplicações e facilidade de uso, possibilitando também rápida informatização.

Outro ponto considerado foi o fato deste método ser relativamente mais simples que os demais, o que também contribui para um melhor entendimento por parte dos tomadores de decisões do Varejo, além de facilitar a aceitação e uso do modelo. 


\subsubsection{Medição de erros nas previsões}

Segundo Ballou (2006), da mesma forma que o futuro não é exatamente espelhado no passado, a previsão da demanda futura incorrerá quase sempre em algum nível de erro (...).

O erro na previsão refere-se a quão perto do verdadeiro nível de demanda chega a previsão. Trata-se daquilo que é corretamente manifestado em estatística como um desvio padrão, uma variância ou um desvio absoluto médio. Sendo, então, definido como erro de previsão:

\section{Erro de previsão $=$ demanda prevista - demanda real}

Dentre os principais métodos de medição de erros em previsões, os seguintes podem ser destacados (Makridakis e Wheelright, 1978) abaixo, obedecendo a seguinte legenda:

$Y_{t}=$ Valor observado da série no período $\mathrm{t}$

$n=$ Número de observações da série usadas na previsão

$\hat{Y}_{t}=$ Valor previsto

1. MAD (Mean absolute deviation): mede a precisão da previsão através das médias dos valores absolutos de cada erro. MAD é mais usado quando os analistas querem medir o erro de previsão na mesma unidade que a da série original.

$$
M A D=\frac{\sum_{t=1}^{n}\left|Y_{t}-\hat{Y}_{t}\right|}{n}
$$

2. MSE (Mean squared error): Cada erro é elevado ao quadrado, todos os erros são, então, somados e divididos pelo número de observações. Esta abordagem penaliza grandes erros de previsão, permitindo ao analista escolher entre a técnica 
que produz erros moderados ou aquela que produz pequenos erros, mas, ocasionalmente, outros extremamente altos.

$$
M S E=\frac{\sum_{t=1}^{n}\left(Y_{t}-\hat{Y}_{t}\right)^{2}}{n}
$$

3. MAPE (Mean absolute percentage errors): Calcula o erro absoluto em termos percentuais; é particularmente útil quando o tamanho da variável de previsão é importante para avaliar a precisão da previsão.

$$
M A P E=\frac{\sum_{t=1}^{n} \frac{\left|Y_{t}-\hat{Y_{t}}\right|}{Y_{t}}}{n}
$$

4. MPE (Mean percentage error): é usado para detectar se o método de previsão possui algum viés. Se positivo, a equação abaixo produzirá percentual próximo a zero; se o resultado for um número negativo alto, a previsão está consistentemente superestimada; caso contrário, o método de previsão está consistentemente subestimando.

$$
M P E=\frac{\sum_{t=1}^{n} \frac{\left(Y_{t}-\hat{Y_{t}}\right)}{Y_{t}}}{n}
$$

O modelo proposto utiliza o MAD como medida padrão, uma vez que se trata do mais amplamente utilizado na literatura. 


\section{REVISÃO BIBLIOGRÁFICA - GESTÃO DE ESTOQUES}

\subsection{DEFINIÇÃO E PROPÓSITO}

Segundo Ballou (2006), estoques são acumulações de matérias-primas, suprimentos, componentes, materiais em processo e produtos acabados que surgem em numerosos pontos do canal de produção e logística das empresa.

Santoro (2006) definiu estoques como a quantidade de bens ou materiais úteis ociosa ou improdutiva sob controle, aguardando uso futuro.

Independentemente da origem de cada definição, a política de estoques integra uma das três principais decisões logísticas junto à localização e transportes (Ballou 2006) e vem ao longo dos tempos aumentando sua importância sob o ponto de vista financeiro e de atendimento ao cliente.

Com relação à categoria, Ballou (2006) classificou os estoques como:

\subsubsection{Canal}

Trata-se de estoques em trânsito nos elos do canal de suprimentos. Onde a movimentação é lenta e/ou as distâncias longas ou onde há muitos elos, o montante de estoque no canal tende facilmente a superar aquele existente nos pontos de depósito, da mesma forma que estoques em processo entre operações de produção podem ser considerados estoques no canal (Ballou, 2006). 


\subsubsection{Especulação}

Como o próprio nome sugere, são estoques mantidos para fins de especulação. Matérias-primas como cobre, outro e prata são compradas tanto para especulação quanto para suprimento das necessidades operacionais.

Onde a especulação com preços ocorre em períodos que superam as necessidades previsíveis da operação, os estoques daí resultantes tornam-se uma preocupação mais do departamento financeiro que da gerência logística (Ballou, 2006).

\subsubsection{Cíclico}

Também chamada de regular, trata-se dos estoques necessários para suprir a demanda média durante o tempo transcorrido entre sucessivos reabastecimentos.

O montante do estoque cíclico é altamente dependente dos tamanhos de lotes de produção, embarques de quantidades econômicas, limitações de armazenamento, prazos de reposição, esquemas referentes a descontos em preços por quantidades e custos de movimentação (Ballou, 2006).

\subsubsection{Obsoleto}

A parte do estoque que se deteriora e fica ultrapassada ou acaba sendo perdida/roubada durante um armazenamento prolongado é chamada de estoque obsoleto ou morto.

Em se tratando de estoques de produtos de alto valor, perecíveis ou fáceis de roubar, é indispensável a adoção de precauções especiais para minimizar o seu volume (Ballou, 2006). 


\subsubsection{Segurança}

Segundo Ballou (2006) trata-se dos estoques formados como um pulmão contra a incerteza na demanda e nos prazos de reposição. Esta quantidade extra, ou estoque de segurança, é um acréscimo ao estoque normal necessário para suprir as condições da demanda acima da média.

O estoque de segurança é determinado por procedimentos estatísticos que lidam com a natureza aleatória da variabilidade presente, seu tamanho depende da extensão desta variabilidade e do nível de disponibilidade de estoque proporcionado.

Para Santoro (2006), o estoque de segurança é função direta do nível de atendimento desejado, isto é, quanto maior o custo do não atendimento, maior deverá ser o nível de atendimento, menores deverão ser as faltas esperadas e consequentemente, maiores deverão ser os estoques de segurança mantidos.

Já Montanheiro e Fernandes (2008) descrevem a fórmula de estoque de segurança baseados em um fator de serviço (FS) (identificado em uma tabela de nível de serviço para função normal), na variação da demanda no decorrer do período $\sigma_{S}$, no lead time (LT) e na periodicidade ou escala de tempo com a qual se calculou o desvio padrão (PP):

$$
E S=F S * \sigma_{S} * \sqrt{(L T / P P)}(7)
$$

Quanto à funcionalidade, Bowersox, Closs e Cooper (2006) sugeriram uma abordagem baseada em quatro funções: especialização geográfica, desacoplamento, balanceamento e incerteza no estoque de segurança, que requerem investimentos em inventário para atender a objetivos gerenciais e operacionais.

Segundo os autores, os inventários planejados e comprometidos com operações somente podem ser reduzidos a um nível compatível com o desempenho das quatro funções do inventário. 
Todos os que ultrapassam esse nível mínimo representam investimentos em excesso. Detalhamento adicional de cada uma das funções pode ser visto na tabela 4.1:

\section{Tabela 4.1 - Funcionalidade do inventário}

\begin{tabular}{c|l}
\hline \multicolumn{2}{c}{ Natureza } \\
\hline Especialização geográfica & $\begin{array}{l}\text { Permite posicionamento geográfico em unidades múltiplas de } \\
\text { distribuição e fabricação. O inventário mantido em diferentes } \\
\text { locais e estágios do processo de criação de valor permite sua } \\
\text { especialização }\end{array}$ \\
\hline Desacoplamento & $\begin{array}{l}\text { Permite: a) economia de escala dentro de uma única } \\
\text { instalação; b) que cada processo opere com eficiência máxima } \\
\text { ao invés de a velocidade do processo inteiro ser reduzida por } \\
\text { causa do mais lento. }\end{array}$ \\
\hline Equilíbrio entre demanda e suprimentos & $\begin{array}{l}\text { Acomoda o lapso de tempo decorrido enter a disponibilidade do } \\
\text { inventário (fabricação, desenvolvimento ou extração) e o } \\
\text { consumo }\end{array}$ \\
\hline Incerteza no estoque de segurança & $\begin{array}{l}\text { Incerteza no recebimento de pedidos ou no seu processamento; } \\
\text { normalmente conhecido como estoque de segurança }\end{array}$ \\
\hline
\end{tabular}

Fonte: Bowersox, Closs e Cooper, (2006)

Santoro (2006) apresentou, na tabela 4.2, uma taxonomia para os modelos de estoques baseada nos trabalhos de Silver (1981), Baransci e outros (1983) e Prasad (1994) e outras novas classes sugeridas pelo próprio.

Tal taxonomia será particularmente útil para apoiar as definições das operações dos modelos de estoque no item 4.4 a seguir. 
Tabela 4.2 - Classificação dos modelos de estoques

\begin{tabular}{|c|c|}
\hline Classe quanto à/ao & Subclasses \\
\hline Uso de previsões & $\begin{array}{l}\text { Reativos } \\
\text { Ativos }\end{array}$ \\
\hline Frequência de revisão & $\begin{array}{l}\text { Periódicos } \\
\text { Contínuos }\end{array}$ \\
\hline Variabilidade de demanda & $\begin{array}{l}\text { Constante } \\
\text { Variável }\end{array}$ \\
\hline Incerteza da demanda & $\begin{array}{l}\text { Determinístico } \\
\text { Estocástico com distribuição conhecida } \\
\text { Estocástico com distribuição desconhecida }\end{array}$ \\
\hline Continuidade da demanda & $\begin{array}{l}\text { Discretos } \\
\text { Contínuos }\end{array}$ \\
\hline Atendimento da demanda & $\begin{array}{l}\text { Sem permissão de faltas } \\
\text { Com permissão de faltas com atraso } \\
\text { Com permissão de faltas como não atendimento } \\
\text { Com permissão de faltas como atraso e não atendimento }\end{array}$ \\
\hline Variabilidade da quantidade pedida & $\begin{array}{l}\text { Fixa } \\
\text { Variável função de nível máximo e atual } \\
\text { Variável função da previsão de demanda }\end{array}$ \\
\hline Tempo de espera & $\begin{array}{l}\text { Zero } \\
\text { Positivo e constante } \\
\text { Variável }\end{array}$ \\
\hline Tempo de espera de emergência & $\begin{array}{l}\text { Sem tempo de espera de emergência } \\
\text { Com tempo de espera de emergência }\end{array}$ \\
\hline Capacidade de oferta & $\begin{array}{l}\text { Infinita } \\
\text { Finita com taxa variável } \\
\text { Finita com taxa constante } \\
\text { Finita com remessa limitada por aquisição } \\
\text { Finita com remessa limitada por período }\end{array}$ \\
\hline Número de itens & $\begin{array}{l}\text { Único item } \\
\text { Múltiplos itens }\end{array}$ \\
\hline Locais de estocagem & $\begin{array}{l}\text { Único } \\
\text { Múltiplos }\end{array}$ \\
\hline Estrutura dos itens & $\begin{array}{l}\text { Sem estrutura } \\
\text { Estrutura linear } \\
\text { Estrutura em árvore }\end{array}$ \\
\hline Horizonte de planejamento & $\begin{array}{l}\text { Finito } \\
\text { Infinito }\end{array}$ \\
\hline Hipóteses sobre funções de custos & $\begin{array}{l}\text { Lineares } \\
\text { Lineares e fixos } \\
\text { Convexas } \\
\text { Outras }\end{array}$ \\
\hline Outras classificações & $\begin{array}{l}\text { Perecíveis e não perecíveis } \\
\text { Com ou sem fração defeituosa } \\
\text { Preços constantes e variáveis com quantidade } \\
\text { Demanda dependente da quantidade em estoque } \\
\text { Demanda crescente ou decrescente } \\
\text { Custo de aquisição conjunto }\end{array}$ \\
\hline
\end{tabular}

Fonte: Santoro, (2006) 


\subsection{CUSTOS DOS ESTOQUES}

Segundo Ballou (2006), o custo de manutenção dos estoques pode representar de $20 \%$ a $40 \%$ do seu valor por ano e, por isso mesmo, administrar cuidadosamente o nível dos estoques é economicamente sensato.

Dentro desta matéria, o autor ainda categoriza os custos em três classes gerais, fundamentais para a determinação da política/modelo de estoques: custos de aquisição, de manutenção e de falta de estoques, permanentemente em conflito, ou em compensação entre si, como poderá ser visto a seguir.

\subsubsection{Custos de aquisição}

Ao se solicitar uma reposição de estoque, incorre-se em uma variedade de custos relacionados ao processamento, preparação, transmissão, manutenção e ao pedido de compra.

Mais especificamente, os custos de aquisição podem incluir preço, ou custo de fabricação do produto conforme as quantidades pedidas; custo da preparação do processo de abastecimento; custo de processamento de um pedido pelos departamentos de compras e contabilidade; custo de transmissão do pedido ao ponto de suprimento, normalmente pela utilização de correios ou meios eletrônicos; custo de transporte do pedido quando não incluídos nos custos variáveis de compra dos produtos; e custo de qualquer manuseio ou processamento dos produtos no ponto de recepção.

Os custos de aquisição estão associados à decisão de repor os estoques e não variam com o tamanho dos lotes (Lustosa et al, 2008). 


\subsubsection{Custos de manutenção de estoque}

São aqueles resultantes do armazenamento ou propriedade de produtos durante um determinado período, proporcionais à média das quantidades de mercadorias disponíveis, divididos em três tipos: custos de espaço, custos de capital, custos de serviço e riscos de estocagem.

\subsubsection{Custos de estocagem e manuseio}

Segundo Lustosa et al (2008), trata-se dos custos de instalações, pessoa e equipamentos dos armazéns, cuja maior parcela varia com o volume dos estoques. Os custos de espaço são cobrados pelo volume no prédio de estocagem.

Para um espaço alugado, as taxas são cobradas por peso e período de tempo; em se tratando de um espaço próprio ou contratado, os custos de espaço são determinados pela alocação de custos operacionais relacionados ao espaço - como calefação, iluminação e equipamento de construção e armazenagem.

\subsubsection{Custos de capital}

Os custos de capital são derivados do custo do dinheiro imobilizado em estocagem, podendo variar entre a taxa máxima de juros e o custo de oportunidade do capital. O custo exato do capital para fins de estoque vem sendo debatido há um bom tempo.

São usados pelas empresas custos médios de capital e taxa média de retorno exigidos pelos investimentos das empresas. Lambert e Lalonde (1976) apontaram a taxa de atratividade como aquela que reflete o custo do capital com maior exatidão. 


\subsubsection{Custos de serviços e riscos de estocagem}

Como custos de serviços de estocagem, é possível destacar seguros e impostos. A cobertura por seguro é feita como garantia contra perdas causadas por incêndios, tempestades ou roubos.

Os custos relacionados com deterioração, roubo, danos ou obsolescência compõem a categoria dos custos com riscos de estocagem. Os custos decorrentes desses estoques podem ser estimados como sendo perda direta de valor do produto, custo do retrabalho do produto, ou como custo do seu fornecimento a partir de um local secundário.

\subsubsection{Custos de falta de estoque}

Tais custos ocorrem quando um pedido não pode ser atendido a partir do estoque ao qual é normalmente encaminhado. Dividem-se em dois tipos: custo das vendas perdidas e custo de pedidos atrasados, que, em decorrência da intangibilidade de sua natureza, torna-se difícil seu cálculo com exatidão.

O custo de venda perdida ocorre quando o cliente, face a situação de falta de estoque, cancela seu pedido. O custo é o lucro que deixa de ser concretizado nessa venda e ainda um adicional decorrente do efeito que essa situação venha a acarretar sobre as vendas futuras.

É importante ressaltar que os produtos para os quais o cliente encontra facilmente alternativas em marcas concorrentes são aqueles mais sujeitos a sofrer prejuízos de vendas perdidas. 
O custo de pedidos atrasados ocorre quando o cliente se dispõe a esperar pelo atendimento do pedido, de maneira que a venda não deixa de ser concretizada, sendo apenas adiada.

Neste caso tais custos são mais tangíveis que os das vendas perdidas, baseando-se em custos adicionais em termos operacionais e de vendas em matéria de processamento, além de custos não programados de transporte e manuseio quando tais pedidos não são atendidos através do canal de distribuição normal.

É importante ressaltar que, estes custos podem carregar um componente intangível relacionado ao impacto em vendas irrealizadas futuras, custo este extremamente difícil de medir.

\subsection{COMPOSIÇÃO DE UM SISTEMA DE GESTÃO DE ESTOQUE}

Os principais componentes do sistema de gestão de estoque, vistos na figura 4.1 podem ser descritos como (Santoro, 2006):

- Tempo de espera (te) ou lead time: trata-se da antecedência para se tomar ou alterar decisões de abastecimento para mais ou menos, supondo continuidade no tempo.

- Tempo de reação ou resposta (tre): é o tempo decorrido entre uma tomada de decisão de abastecimento e a próxima data em que se pode influenciar fisicamente o estoque, nos modelos periódicos tre $=$ te $+\operatorname{pr}$ (periodo de revisão), nos modelos contínuos tre = te, uma vez que neste último caso o período de revisão é igual a zero. 


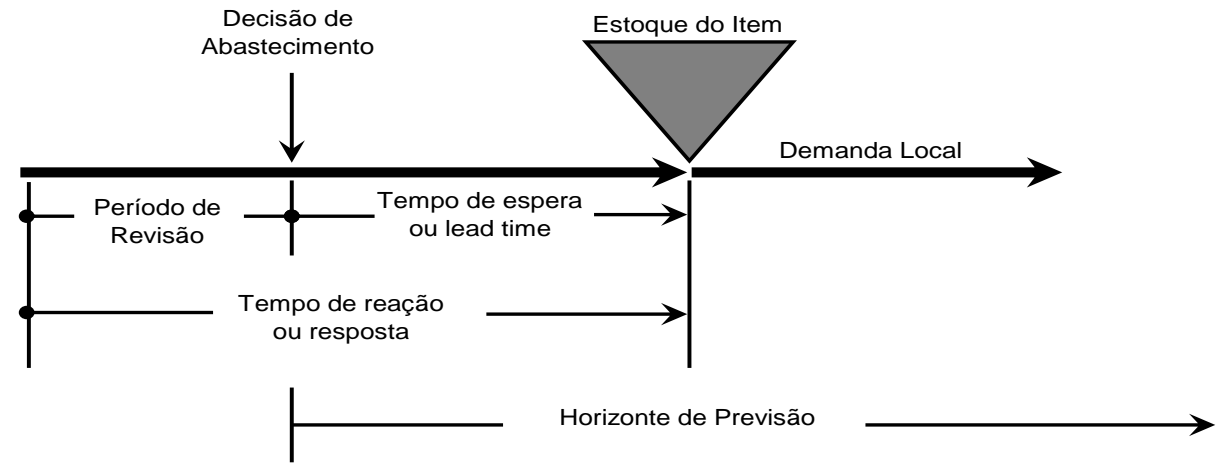

Figura 4.1 - O problema físico do estoque. Fonte: Santoro (2006)

\subsection{MODELOS DE REPOSIÇÃO DE ESTOQUE}

Segundo Santoro (2006), a gestão de estoques consiste em se decidir o quê, quando e quanto comprar, de forma a atender da melhor maneira possível os objetivos múltiplos de minimização de faltas, de investimento em estoque e de número de aquisições, obedecendo às restrições de nível mínimo de atendimento e investimento no sistema global de estoque.

\section{$\begin{gathered}\text { Estoque } / \\ \text { Falta Inicial }\end{gathered}+$ Compras $-\begin{gathered}\text { Vendas } \\ \text { Previstas }\end{gathered}=\begin{gathered}\text { Estoque } / \\ \text { Falta Final }\end{gathered}$}

Figura 4.2 - Relacionamento entre as decisões. Fonte: Santoro (2006)

Tais variáveis de decisão (o que, quando e como comprar) são consequência direta da escolha do modelo de reposição de estoque utilizado para o abastecimento da empresa em questão.

Entre os diversos modelos existentes, Santoro (2006) destacou os seguintes na tabela 4.3 apoiada pela legenda a seguir, que será utilizada no detalhamento de cada um deles: 
Tabela 4.3 - Exemplos de modelos de estoque

\begin{tabular}{cccc|ccccc}
\hline \multirow{2}{*}{ Parâmetros } & \multicolumn{3}{c}{ Periódicos } & \multicolumn{2}{c}{ Reativos } & \multicolumn{2}{c}{ Ativo } \\
& REPMAXP & REPBASP & LOTFIXP & REPMAXC & Contínuos & REPBASC & LOTFIXC & Periódico \\
& CALNEC \\
\hline PerRev & $\mathbf{X}$ & $\mathbf{X}$ & $\mathbf{X}$ & & & & \\
\hline PtoPed & $\mathbf{X}$ & & $\mathbf{X}$ & $\mathbf{X}$ & & $\mathbf{X}$ & \\
\hline EstMax & $\mathbf{X}$ & $\mathbf{X}$ & & $\mathbf{X}$ & $\mathbf{X}$ & & \\
\hline LotFix & & & $\mathbf{X}$ & & & $\mathbf{X}$ & \\
\hline EstSeg & $\left(^{*}\right)$ & $\left(^{*}\right)$ & $\left(^{*}\right)$ & $\left(^{*}\right)$ & $\left(^{*}\right)$ & $\left(^{*}\right)$ & $\mathbf{X}$ \\
\hline
\end{tabular}

$\left(^{*}\right)$ Estoque de segurança contido em outros parâmetros

\section{Fonte: Santoro (2006)}

Onde:

REPMAXP: Reposição pelo máximo periódico REPBASP: Reposição da base periódico

LOTFIXP: Lote fixo periódico

CALNEC: Cálculo das necessidades

EstMax: Estoque máximo

EstSeg: Estoque de segurança
REPMAXC: Reposição pelo máximo contínuo REPBASC: Reposição da base contínuo LOTFIXC: Lote fixo contínuo

PerRev: Período de revisão

LotFix: Lote fixo

A seguinte legenda apoiará a discussão dos próximos tópicos:

EstFis = Estoque físico

EstFisARec $=$ Estoque físico a receber OCompra $=$ Quantidade a comprar

(compras ainda não recebidas)

(calculada no instante da decisão)

$T=$ Período de revisão

$\mathrm{S}=$ EstMax $=$ Estoque máximo

$\mathrm{S}=$ PtoPed $=$ Ponto de pedido

$\mathrm{Q}=\mathrm{q}=$ LotFix $=$ Tamanho de lote de compra

\subsubsection{Modelos Reativos}

A principal diferença entre os modelos ativos e reativos é a utilização, pelos ativos, de uma previsão de demanda como parte das informações consideradas na tomada de decisão de um sistema de estoque (o que comprar, quando comprar, quanto comprar).

Os modelos reativos são classificados por periódicos e contínuos de acordo com período de revisão. Segundo Santoro (2006), a operação dos modelos reativos, periódicos ou contínuos, se dá através de procedimento simples que tem como base 
os parâmetros: período de revisão, ponto de pedido, estoque máximo e lote fixo. Tais modelos possuem o estoque de segurança contido em outros parâmetros.

\subsubsection{REPMAXP - Reposição do máximo periódico}

Como definido por Silver e Peterson (1985), este modelo é uma combinação dos sistemas $(\mathrm{s}, \mathrm{S})$ e $(\mathrm{T}, \mathrm{S})$, conhecido como revisão periódica, baseado no sistema $(\mathrm{T}, \mathrm{S}, \mathrm{S})$

Segundo Silver e Peterson (1985), a idéia é que, a cada (R) unidades de tempo, seja checada a posição do estoque. Se houver atingido ou estiver abaixo do ponto de pedido (s), um pedido é feito para levar o estoque à posição (S) ou nível máximo de estoque. Caso a posição do estoque no momento da comparação esteja acima de (s), nada é feito até o próximo instante de revisão.

Freire (2007) concluiu que, por permitir lotes de tamanhos variados com estoque médio inferior ou igual ao estoque máximo, esta política torna adequada a implementação de estratégias onde o capital investido em estoque possua um valor máximo como limite.

Segundo Santoro (2006), a regra de decisão para esta política pode ser definida como:

$$
\begin{aligned}
\text { OCompra }= & (\text { EstMax }- \text { EstFisARec }) \text { se EstFisARec }<=\text { PtoPed } \\
& 0 \text { (zero }) \quad \text { se EstFisARec }>\text { PtoPed }
\end{aligned}
$$

4.4.1.2 REPMAXC - Reposição do máximo contínuo

Silver e Peterson (1985) definiram tal modelo como revisão contínua baseada no sistema $(\mathrm{s}, \mathrm{S})$. A dinâmica desse modelo pode ser descrita como aquela em que a 
reposição é feita toda vez que o estoque atinge o ponto de pedido (s) ou abaixo, sendo a quantidade pedida suficiente para elevar a posição do estoque ao nível (S) ou nível máximo do estoque.

Como definido por Freire (2007), a diferença entre ambos os modelos, contínuo e períodico, está no momento da decisão: no modelo periódico, é tomada ao final do período de revisão, enquanto que no modelo contínuo é tomada sempre que o estoque físico a receber tornar-se menor que o ponto do pedido.

\subsubsection{REPBASP e REPBASC - Reposição da base periódico e contínuo}

Este modelo bastante tradicional é chamado de estoque base. Definido por Lustosa et al (2008, p. 94): "Trata-se de um caso particular do modelo de ponto de pedido e também do modelo de revisão periódica, pois seu parâmetro, o estoque base, funciona como uma quantidade máxima a ser mantida no sistema (...) sendo contínua a revisão do estoque".

Esta definição é aplicada ao modelo REPBASC que se diferencia do modelo REPBASP somente quanto ao momento da decisão, que no modelo periódico é tomada ao final do período de revisão. Segundo Santoro (2006), a regra de decisão deste modelo pode ser descrita como:

$$
\text { OCompra }=\text { EstMax }- \text { EstFisARec }
$$

Freire (2007) destacou que este modelo é extremamente sensível ao custo do pedido, uma vez que ordena a reposição em todo o período de revisão.

Segundo Santoro (2006), o modelo de reposição da base contínuo deu origem ao Kanban. Em ambas as versões, periódico e contínuo, o ponto de pedido e o estoque máximo são iguais. 


\subsubsection{Lote fixo periódico e contínuo (Lote Econômico ou LEC)}

Lote fixo ou tamanho de lote são modelos baseados no sistema (s, q) (Naddor, 1966) ou (s, Q) (Silver e Peterson, 1985). Assim como nos demais modelos, a diferença entre periódico e contínuo está no fato do periódico tomar a decisão após o período de revisão.

A dinâmica destes modelos se dá quando uma determinada quantidade fixa $Q$ ou um múltiplo é pedida no momento em que o nível de estoque disponível é menor ou igual ao ponto de pedido s.

Importante ressaltar que é a posição do inventário que usada para acionar um novo pedido, e não o inventário líquido, uma vez que a posição do inventário considera os pedidos em trânsito, já requeridos porém não recebidos ainda (Silver e Peterson, 1985).

Harris (1913) desenvolveu um modelo para encontrar a quantidade ótima de pedido, que se tornou conhecido como a fórmula básica da quantidade econômica do pedido ou EOQ.

Tal fórmula é desenvolvida a partir de uma equação de custo total envolvendo custo de aquisição e custo de manutenção de estoques.

Santoro (2006) descreve a regra de decisão como:

$$
\begin{array}{ccc}
\text { OCompra }= & \mathrm{n} \times \text { LotFix } & \text { se EstFisARec }<\text { PtoPed } \\
0 \text { (zero) } & \text { se EstFisARec }>\text { PtoPed }
\end{array}
$$

Sendo $\mathrm{n}$ um número inteiro mínimo que garante após a compra EstFisARec >= PtoPed

Segundo Lustosa et al (2008), considerando que, nesta política, quanto maior o custo do pedido, maior o tamanho do lote (e menor a frequência de pedidos), a 
redução no custo do pedido deve ser vista como prioritária nos esforços de gestão para melhoria de sua eficiência, pois proporcionará a redução dos lotes e consequentemente a redução do custo total.

\subsubsection{Modelo Ativo}

Conforme introduzido na seção anterior, a principal diferença entre os modelos ativos e reativos é a utilização de uma previsão de demanda no modelo de estoque, motivo pelo qual a revisão bibliográfica foi iniciada por tal matéria.

Em virtude de dois dos modelos de estoque utilizados neste trabalho basearem-se em previsões de demanda - CALNEC e o modelo atualmente utilizado pelo Varejo foi necessário discorrer sobre as técnicas de previsão de demanda, já descritas no capítulo 3.

Na sequência, segue a descrição do modelo CALNEC, o modelo do Varejo será detalhado na seção posterior

\subsubsection{Cálculo das necessidades (CALNEC)}

Cálculo das necessidades é um modelo baseado em MRP (Material requirement planning) amplamente discutido através da literatura em De Bodt and Van Wassenhove (1983), Anderson et al (1982), Billington et al (1983), entre outros, tendo se tornado a base para os sistemas de manufatura contemporâneos.

As primeiras aplicações do cálculo das necessidades foram desenvolvidas nos EUA nos anos 60. Segundo Orlicky (1975), o planejamento de requerimento de material (MRP) é a filosofia mais abrangente usada para lidar com planejamento de produção multi-estágios. 
Hax e Candea (1984) definem o MRP como um sistema que trata de uma coleção de procedimentos lógicos para gerenciar em maior nível de detalhe, estoques de produtos acabados, semi-acabados e matéria-prima num ambiente de manufatura de maneira hierárquica (...).

A "explosão" tem sido mencionada como o mecanismo no qual as necessidades para cada item ou matéria-prima de cada componente são calculadas, nível a nível.

A necessidade líquida, é determinada pelo resultado final entre a necessidade bruta subtraídos o estoque existente e o estoque em trânsito (já solicitado).

Santoro (2006) sugeriu a seguinte aplicação da idéia do modelo de cálculo das necessidades, adaptado ao problema dos estoques, no qual não existe uma estrutura de item:

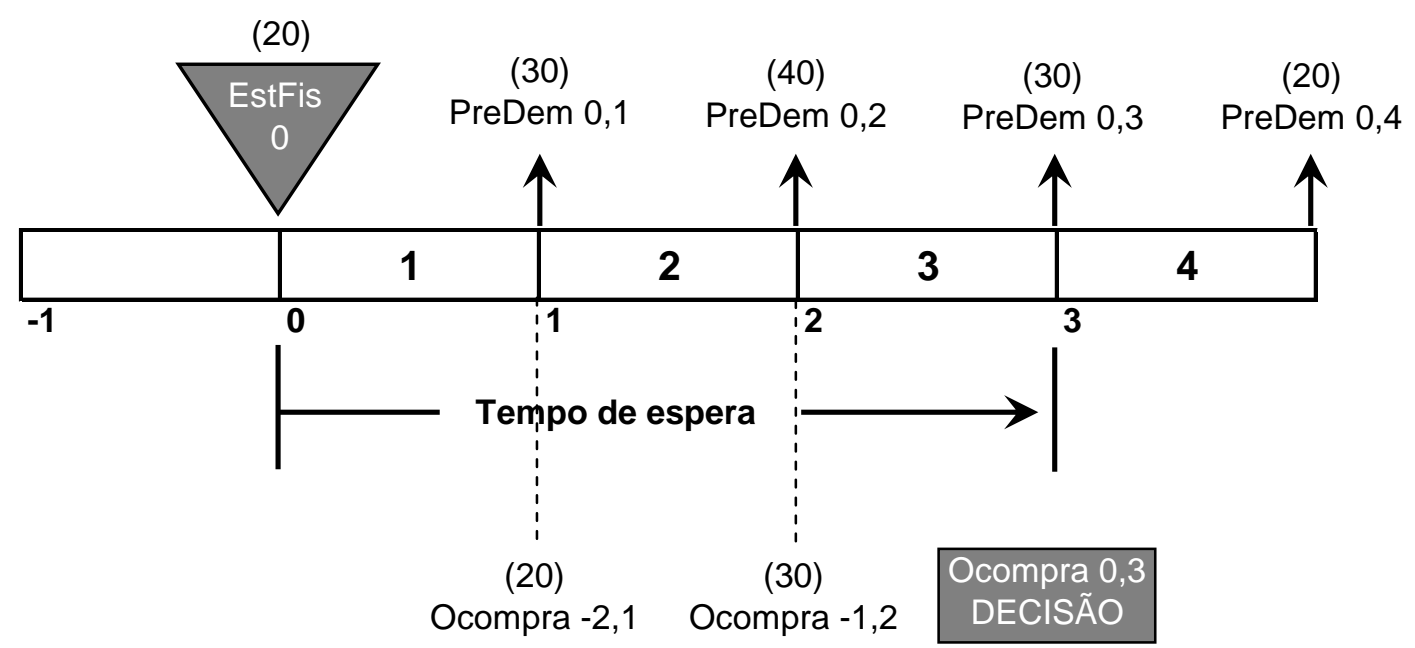

Figura 4.3 - Operação do modelo ativo. Fonte: Santoro (2006)

Onde:

PreDem $t, p=$ previsão de demanda feita em $t$, referente ao período $p$ adiante NLiq $t, p=$ necessidade líquida em $t$ a ser entregue no final de $p$ períodos adiante

OCompra $t, p=$ quantidade a comprar decidida em $\mathrm{mt}$ a ser entregue no final de $\mathrm{p}$ períodos adiante

A decisão de compra é tomada a partir do cálculo da necessidade líquida no instante zero com previsão para chegar na data 3 e tornar o estoque na data 4 igual ao estoque de segurança - e é feita da seguinte maneira (Santoro 2006): 


$$
N L i q_{t, t+t e}=\sum_{i=1}^{t r e} \operatorname{Pr} e \operatorname{Dem}_{t, t+i}-\sum_{i=1}^{t e-1} \text { OCompra }_{t+i-t e, t+i}-\text { EstFis }_{t}+\text { EstSeg }
$$

Desta forma, o procedimento de decisão no final dos períodos será:

$$
\begin{array}{ll}
\text { OCompra } 0,3= & \text { NLiq } 0,3 \\
0 & \text { se NLiq } 0,3>0 \\
0 & \text { se NLiq } 0,3<0
\end{array}
$$

É importante ressaltar que os estoques de segurança estão diretamente associados ao nível de atendimento e aos erros de previsão. Em geral, tais estoques são calculados a partir da distribuição de tais erros.

Montanheiro e Fernandes (2008) aplicaram em uma confecção de roupas as técnicas de gerenciamento de estoques com foco na elaboração de lotes econômicos.

Com a elaboração de lotes econômicos de compra, estoque de segurança e ponto de reposição, obtiveram como resultados a redução de problemas com a descontinuidade de produção por falta de materiais, além de possibilitar uma compra de forma mais econômica.

Junior (2009) também utilizou lote econômico para a gestão de estoques em uma empresa de varejo no nordeste brasileiro. A mais importante contribuição deste último autor foi o desenvolvimento de um procedimento simplificado para a determinação de nível de estoque ideal.

O trabalho de Hayes (1994) concentrou-se num estudo de caso em um centro de geração de fotocópias numa escola no Colorado. Para apoiar a gestão de estoques, utilizou um modelo ativo cuja previsão semanal baseava-se no método de Winters.

As ordens de compra eram feitas via lote fixo utilizando uma heurística de Silver e Meal de forma a acomodar os limites de espaço de armazenamento físico; embora tal heurística tenha apresentado desempenho insatisfatório para casos em que a 
demanda histórica tenha sido zero, através de alguns ajustes nestas regras, alcançaram resultados satisfatórios junto à gerência envolvida neste estudo.

Dias e Yoshizaki (2000) trouxeram importantes contribuições na análise de sistemas de gestão de estoques em ambiente multicamada. Seu trabalho baseou-se em simulações efetuadas através de seis cenários distintos cobrindo a seguinte cadeia: laboratório farmacêutico => distribuidores => farmácias.

A reposição dos estoques do laboratório foi feita utilizando ponto de reposição; a dos distribuidores, cálculo das necessidades; e a das farmácias, distribuições de probabilidade considerando bases históricas.

O melhor cenário apresentou redução de custo total na cadeia de $72,1 \%$, conseqüência direta da redução de estoque de $89,7 \%$ nos distribuidores, segundo os autores, decorrentes de aumento de periodicidade de entrega, implementação de métodos quantitativos de previsão de demanda e eliminação de compras especulativas motivadas por políticas comerciais de premiação de grandes lotes de compra.

Vineyard et al (1997) implementaram um modelo de planejamento de capacidade e inventário para a divisão de Luz, Gás e Água de Memphis e Tenesee.

Esta é baseada na regressão múltipla para apoiar a previsão de demanda de gás fornecido principalmente para aquecimento de residências e empresas industriais que tinham o gás como alternativa ao combustível padrão.

A utilização de um processo formal de previsão de demanda, aliado à construção de um portfólio robusto de fornecedores para programação dos recursos necessários em diferentes épocas do ano, trouxe economias significativas a esta divisão: aproximadamente US\$6,1 milhões conforme observado pelos autores.

Filho e Fernandes (2009), em seu estudo de caso sobre o sistema MRP (Material Requirement Planning), envolvendo uma grande empresa multinacional produtora de material escolar, teve por foco a integração do planejamento e do agendamento de 
produção e a reparametrização de diversos componentes do sistema, entre eles os métodos de previsão de demanda e gestão de estoques.

Para previsão de demanda, o principal ajuste feito foi a alteração da técnica de médias simples sem métodos de medição de erros para outros métodos mais sofisticados (os autores não relacionaram quais), com medição sistemática de erros via MAD.

Com relação à gestão de estoques, a principal alteração efetuada foi a mudança da política de tamanhos de lotes de forma a reduzir inventário, lead time e instabilidades no sistema. Foi adotada uma política de lote para lote para produto acabado e método LTC para semi-acabados.

Os resultados demonstraram redução total nos custos dos estoques em torno de $39 \%$ e principalmente redução drástica na instabilidade do sistema de 85,9\%. 


\section{MÉTODO}

A presente pesquisa é centrada em modelagem quantitativa caracterizada pelo desenvolvimento, análise e testes de relações causais entre variáveis de controle e desempenho.

É chamada de pesquisa axiomática quantitativa, em contraposição ao que se chama pesquisa empírica. Nessa classe de pesquisa, procura-se, através da exploração do funcionamento de um modelo, obter conhecimento sobre a estrutura do problema estudado (Bertrand e Fransoo, 2002).

Segundo Gil (1991), do ponto de vista de natureza, trata-se de uma pesquisa aplicada, uma vez que objetiva gerar conhecimento para aplicação prática dirigidos à solução de problemas específicos, envolvendo verdades e interesses locais, ao contrário de uma pesquisa de natureza básica.

Com relação a procedimentos técnicos, Gil (1991) a define ainda como uma pesquisa experimental, pois desenvolve-se através da determinação do objeto de estudo, da seleção das variáveis capazes de influenciá-lo, da definição das formas de controle e da observação dos efeitos que a variável produz no objeto.

Através da abordagem quantitativa, serão utilizados dados de um problema real, de forma a permitir uma experimentação. Para isso, foi utilizado um modelo de apoio à decisão, desenvolvido em Microsoft Excel e VBA, que apoiou o procedimento experimental.

Segundo Cauchick (2010), os modelos permitem compreender melhor o ambiente em questão, identificar problemas, formular estratégias e oportunidades, apoiar e sistematizar o processo de tomada das decisões. 


\section{PROCEDIMENTO EXPERIMENTAL}

Como já introduzido em capítulos anteriores, o modelo de decisão, objeto deste trabalho, é composto por um módulo de gestão de estoques apoiado em um outro módulo de previsão de demanda, de forma a gerar as informações necessárias aos modelos de estoque ativos.

Ambos os módulos são componentes do SGE (sistema de gestão de estoques), cedido para esta pesquisa pelo programa de Pós-graduação de Engenharia de Sistemas Logísticos da EPUSP.

Assim como em Santoro (2006), a classe de modelo escolhida para efetuar tais previsões neste sistema foi a do modelo de projeção, que trata dos modelos quantitativos e estatísticos, admitindo que o futuro será uma reprodução do passado, não existindo preocupação em se conhecer as causas da demanda (...).

Esta classe de modelo foi a escolhida em detrimento das demais (explicação e predição), uma vez que o sistema de gestão foi desenvolvido para atender a situações em que o número de itens é muito grande.

Tal número torna impraticável o uso de modelos de explicação baseados em funções causais, que exigiriam a previsão de variáveis independentes e tornariam o problema de porte multiplicado. Da mesma forma, torna inviável o uso dos modelos de predição qualitativos, pois seria impraticável o tratamento individualizado dos itens.

O processo de coleta de dados primários teve como objetivo suprir o módulo de previsão com os dados requeridos para seu funcionamento básico, de forma a alimentar os modelos de estoques ativos com previsões de demanda dos itens para tomada de decisão de compra. 
Como Hanke e Reitsch (1998) afirmaram, uma das etapas mais difíceis e que mais consomem tempo do processo de previsão é a coleta de dados válidos e confiáveis. Uma previsão não pode ser mais precisa que os dados nos quais é baseada, não importa quão sofisticado seja o modelo.

Quatro critérios podem ser aplicados para a determinação da utilidade do dado (Hanke e Reitsch, 1998):

- O dado deve ser confiável e preciso

- O dado deve ser relevante

- O dado deve ser consistente

- O dado deve ser disponibilizado em tempo hábil

Desta forma, a coleta de dados com a finalidade de selecionar a amostra de trabalho consistiu na extração destes diretamente da base de dados disponibilizada pelo varejo às indústrias fornecedoras de bens de consumo.

Esta amostra foi composta por 716 dias consecutivos de dados de vendas e estoques para cinco SKUs e dez lojas, num total de 71.600 dados, tendo sido 716 dias a maior faixa de histórico disponível naquele momento, cobrindo o período de 30 de dezembro de 2008 a 16 de dezembro de 2010.

Os dados foram coletados na base diária para apoiar a aplicação do modelo cujos pedidos poderão ser efetuados em frequência diária se necessário.

A seleção das lojas e SKUs envolvidos na amostra tiveram como critério básico os diferentes níveis de volume de venda e geografias, com a finalidade de entender se pode existir alguma relação com os resultados gerados pelo sistema de gestão de estoques.

Os detalhes do processo de seleção da amostra podem ser vistos na seção 6.1.

Considerando que tal amostra consistia em dados brutos, sem nenhum tipo de tratamento, foi necessário efetuar uma análise preliminar para entender 0 
comportamento destes dados quanto a picos, vales e faltas no que diz respeito aos dados de vendas.

Também foi necessária uma análise relativa a erros encontrados nos dados de estoque, causados por falha humana durante o processo de recebimento dos produtos nas lojas, por exemplo, bastante comum no segmento varejista.

Uma vez identificados e quantificados devidamente, as situações encontradas desta amostra foram submetidos a tratamento específico para cada tipo, de forma a proporcionar, se não a eliminação do efeito, a redução significativa dos mais representativos sobre o total desta base.

A seção 6.2 descreve o procedimento completo de tratamento preliminar de dados.

A análise dos padrões de dados foi efetuada através da aplicação da ferramenta de autocorrelogramas às 50 combinações de SKU x loja da amostra, com a finalidade de identificar o nível de adesão destes dados a padrões como sazonalidade, tendência e aleatoriedade, assim como sua distribuição nesta amostra.

Idealmente, o histórico mínimo necessário para avaliar sazonalidades deveria ser de três anos (aproximadamente 1.095 dias de dados históricos), porém não foi possível conseguir tal quantidade de dados devido a restrições do sistema do varejo.

Em função disso, não foram efetuadas análises de sazonalidades anuais. Esta análise foi particularmente importante para confirmar se a escolha pela aplicação dos modelos temporais e quantitativos foi acertada, uma vez que tais padrões tenham sido evidenciados na série de dados.

Os detalhes envolvidos nesta análise podem ser vistos mais adiante na seção 6.3.

Uma vez definida a amostra, aplicado o tratamento aos dados e identificados os padrões existentes, o passo seguinte foi a aplicação do modelo de gestão embutido no SGE (Sistema de gestão de estoque) a esta amostra. 
Este sistema possui um algorítmo bastante complexo, que suporta um nível alto de flexibilidade, tendo sido desenvolvido pelo Programa de pós-graduação Engenharia de Sistemas Logísticos da EPUSP para fins de pesquisa acadêmica.

Não serão exploradas através deste trabalho todas as possibilidades previstas neste sistema, e sim os atributos suficientes para o atingimento do objetivo desta pesquisa.

Como explicado por Santoro (2006), o software desenvolvido considerou curvas de demanda constante, inclinada crescente ou decrescente, constante com sazonalidade, inclinada crescente e decrescente com sazonalidade.

Dentre os modelos de estoque contemplados no SGE, encontram-se os reativos e ativos, periódicos e contínuos, entre os principais abordados na literatura e cobertos em nossa revisão bibliográfica.

Além disso, todo o sistema permite parametrização para análise da sensibilidade com respeito a custos de pedidos, armazenagem e falta, assim como nível de atendimento, entre outros.

A seção 6.4 foi dedicada à descrição mais completa dos procedimentos de previsão de demanda, alocação do modelo de estoque e detalhamento adicionado do SGE.

A parametrização utilizada no sistema baseou-se nas informações de nível de serviço (mínimo), custos de pedidos e armazenagem. Não foi utilizado o parâmetro de custo de falta, embora o sistema estivesse preparado para tal, em virtude da complexidade no cálculo deste valor. Desta forma, o custo final foi considerado como quase total

Como pode ser visto na figura 6.1, o arranjo experimental do SGE é basicamente formado por uma rotina de busca com simulação, de forma a encontrar os melhores parâmetros para cada modelo de previsão de acordo com a amostra de dados utilizada. 
Esta mesma rotina efetuou o cálculo dos desvios de previsão através do método de previsão de erros MAD (Mean absolute deviation) para cada combinação de SKU x loja e, em seguida, classificou os modelos de melhor para pior de acordo com o desempenho do MAD para cada combinação.

Uma vez que o melhor modelo de previsão foi identificado, estas informações alimentaram a segunda rotina de busca e simulação, responsável por identificar os melhores parâmetros para cada modelo de estoque avaliado e aplicado a cada um dos pares SKU x loja.

Nesta etapa, foram produzidos, entre os diversos dados de saída do sistema, o estoque médio e o número de pedidos necessários ao funcionamento de cada modelo.

Com base nestes dados, o sistema pode efetuar o cálculo do custo operacional total através da aplicação dos parâmetros de custo por pedido e armazenagem. Após este processo, os modelos foram classificados de melhor para pior através do valor do custo operacional total.

Importante mencionar que, embora o SGE possuísse uma rotina adicional para geração das séries de demandas para pesquisa, esta não foi utilizada para este trabalho, uma vez que, para a validação da hipótese desta pesquisa, foi necessária a utilização de dados reais do varejo.

Como descrito em Freire (2007), o relatório de saída foi composto pelos valores ótimos dos parâmetros dos modelos de previsão e estoques, simulados para cada item, bem como os resultados dos custos totalizados e a classificação de cada modelo. 


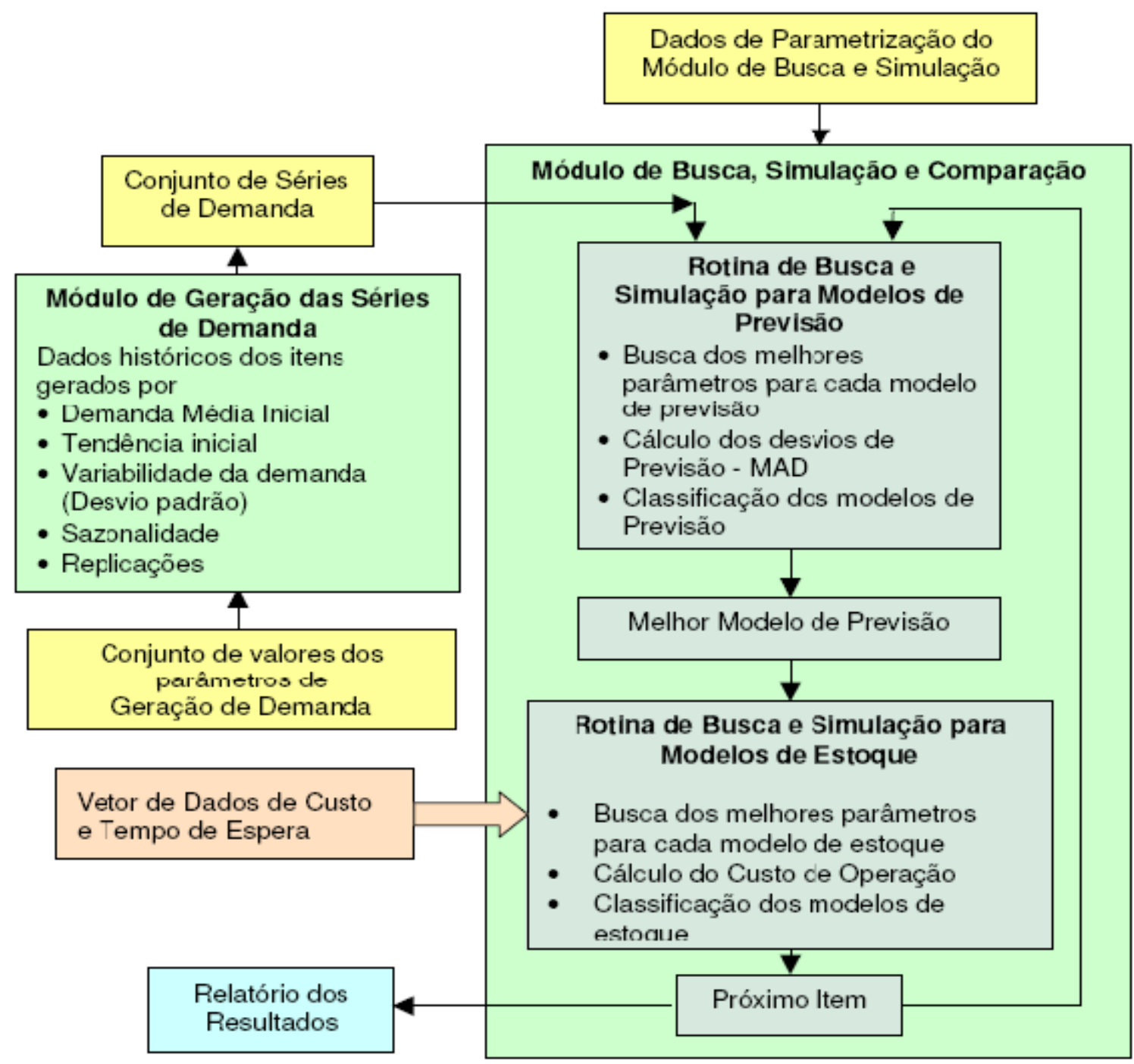

Figura 6.1 - Arranjo experimental utilizado no SGE. Fonte: Freire (2007)

O SGE foi construído sobre a plataforma Microsoft Excel 2000 e sua programação foi desenvolvida em VBA (Visual Basic for Applications) apoiada em planilhas de Excel utilizadas para a entrada e saída dos dados (Freire, 2007).

A configuração computacional utilizada para efetuar as sucessivas execuções pode ser vista abaixo. Cada execução foi efetuada com tempo médio de 15min:

- Processador Intel(R) Core(TM)2 Duo CPU T5450

- 1.66GHz, 1667 Mhz, 2 Núcleo(s), 2 Processador(es) Lógico(s)

- Sistema operacional Microsoft ${ }^{\circ}$ Windows Vista ${ }^{\mathrm{TM}}$ Home Basic

- Memória virtual total de 2,24 GB 
Faz parte do procedimento experimental:

- Efetuar quatro execuções do SGE para todas as combinações de SKU x loja, no total de 50. Cada execução teve como parâmetro de nível de atendimento os valores $0,89,0,92,0,95$ e 0,98 , mantendo-se os parâmetros de custo de pedido e armazenagem.

- Efetuar a análise dos resultados da modelagem no que diz respeito aos modelos de previsão de vendas e modelos de estoque, desde a visão geral até o detalhe SKU e loja, incluindo as variáveis volume de venda e geografia.

- Efetuar a análise de sensibilidade quanto à variação do parâmetro de nível de atendimento.

\subsection{SELEÇÃO DA AMOSTRA DE TRABALHO}

\subsubsection{Critérios para seleção das lojas}

Foram selecionadas dez lojas representando cerca de $15 \%$ do volume total de venda do varejo utilizando como base a maior diversidade possível dentre os critérios pré-estabelecidos.

Os principais critérios utilizados para seleção das lojas foram os seguintes: localização geográfica, volume médio de venda e formato de loja, como pode ser visto na tabela 6.1: 
Tabela 6.1 - Classificação das lojas da amostra

\begin{tabular}{ccc}
\hline $\begin{array}{c}\text { Código } \\
\text { loja }\end{array}$ & Cidade & $\begin{array}{c}\text { Classificação por volume } \\
\text { de Venda }\end{array}$ \\
\hline Loja1 & Recife & médio \\
\hline Loja2 & Aracaju & baixo \\
\hline Loja3 & Salvador & baixo \\
\hline Loja4 & Rio de Janeiro & baixo \\
\hline Loja5 & Porto Alegre & alto \\
\hline Loja6 & Vitória & médio \\
\hline Loja7 & Ribeirão Preto & médio \\
\hline Loja8 & Curitiba & alto \\
\hline Loja9 & Belo Horizonte & médio \\
\hline Loja10 & Brasília & baixo \\
\hline
\end{tabular}

\subsubsection{Localização geográfica}

Foram selecionadas lojas de distintas regiões geográficas - nordeste (três), sudeste (quatro), sul (duas) e centro-oeste (uma) - com a finalidade de avaliar neste modelo diferentes comportamentos de venda em diversas regiões do Brasil.

Diretamente relacionado à localização geográfica está o tempo de entrega, que corresponde à quantidade de tempo necessária desde o faturamento do pedido até a entrega definitiva na loja em dias.

\subsubsection{Classificação por volume de venda}

Trata-se do volume total de venda no período considerando todos os SKUs em cada loja, em unidades de venda. Para simplificar esse critério, foi desenvolvida a seguinte classificação: 
Tabela 6.2 - Critério para classificação das lojas

\begin{tabular}{cc}
\hline $\begin{array}{c}\text { Volume de venda } \\
\text { (unidades no período } \\
\text { avaliado em milhares) }\end{array}$ & $\begin{array}{c}\text { Classificação por } \\
\text { volume de Venda }\end{array}$ \\
\hline$<25$ & baixa \\
\hline $25<x<40$ & média \\
\hline $40<$ & alta \\
\hline
\end{tabular}

\subsubsection{Critério para seleção dos SKUs}

Foram selecionados cinco SKUs representando cerca de $10 \%$ do volume de venda. Trata-se de produtos não perecíveis, dentre os quais produtos de higiene e limpeza.

Dentre os critérios selecionados para classificação dos SKUs, foi utilizado o volume médio de venda, que permitiu classificar os SKUs entre alto, médio e baixo volume, como pode ser visto na tabela abaixo:

Tabela 6.3 - Classificação dos SKUs da amostra

\begin{tabular}{cc}
\hline $\begin{array}{c}\text { Código do } \\
\text { SKU }\end{array}$ & $\begin{array}{c}\text { Classificação por } \\
\text { volume de venda }\end{array}$ \\
\hline SKU1 & alto \\
\hline SKU2 & medio \\
\hline SKU3 & baixo \\
\hline SKU4 & baixo \\
\hline SKU5 & alto \\
\hline
\end{tabular}


6.1.2.1 Classificação por volume de venda

A classificação por volume médio de cada SKU foi desenvolvida da seguinte forma, de acordo com a tabela abaixo:

Tabela 6.4 - Critério para classificação dos SKUs

\begin{tabular}{cc}
\hline $\begin{array}{c}\text { Volume de venda } \\
\text { (unidades no período } \\
\text { avaliado em milhares) }\end{array}$ & $\begin{array}{c}\text { Classificação por } \\
\text { volume de Venda }\end{array}$ \\
\hline$<50$ & baixa \\
\hline $50<x<65$ & média \\
\hline $65<$ & alta \\
\hline
\end{tabular}

\subsection{TRATAMENTO DOS DADOS}

Através de uma análise preliminar nos 71.600 (venda e estoque em 716 dias por cinco SKU e dez lojas) dados da amostra, foram identificados diversos tipos distintos de situações, sendo que somente as mais representativas foram de fato tratadas, como consta na tabela 6.5 . 
Tabela 6.5 - Resultado da análise de situações identificadas na amostra de dados

\begin{tabular}{cc}
\hline Situação & $\begin{array}{c}\% \text { de representatividade sobre a } \\
\text { quantidade total de dados }\end{array}$ \\
\hline Falta: $\quad$ Estoque no dia $=0$ & $10,7 \%$ \\
\hline Pré-falta: $\begin{array}{c}\text { Cobertura de estoque }< \\
1 \text { dia }\end{array}$ & $3,8 \%$ \\
\hline Picos de Venda & $19,3 \%$ \\
\hline Venda negativa & $0,1 \%$ \\
\hline Estoque negativo & $1,0 \%$ \\
\hline $\begin{array}{c}\text { Venda no dia com estoque } 0 \text { antes } \\
\text { e } 0 \text { no dia da venda }\end{array}$ & $1,6 \%$ \\
\hline
\end{tabular}

\subsubsection{Falta e pré-falta}

A primeira parte da análise foi dedicada a entender as situações nas quais a venda no dia era zero.

Assim, considerando que a amostra cobre lojas que permanecem abertas vinte e quatro horas por dia, restam as situações relacionadas ao balanço (normalmente ocorrem a cada três meses), feriados ou mesmo dias onde não houve, de fato, vendas por falta de demanda.

Para localizar estas situações, foram identificadas na base de dados todos os casos de venda no dia igual a zero. Para todos estes casos, foram selecionados aqueles em que a venda era igual a zero, porém havia estoque disponível um dia antes e um dia após, na mesma ou em maior quantidade se comparado com a quantidade de estoque do dia anterior. 
Com base nesta regra, foram desconsideradas do restante da análise as situações em que a falta da venda é legítima (por falta de demanda), não representando, desta forma, ruptura de estoque.

As demais situações de faltas foram, então, avaliadas pontualmente na tentativa de identificar prováveis causas, entre elas, planejamento incorreto de promoções e erro na previsão de demanda (ou na parametrização do sistema de reabastecimento), num total de $10,7 \%$ (\% de casos de faltas sobre o total dos dados de vendas).

Para estes casos, a venda zerada foi substituída pela venda média do SKU por loja daquele dia da semana (Vmed.dia), específico para corrigir cada uma destas situações.

O passo seguinte foi a identificação de situações de pré-falta propriamente ditas. Tal validação utilizou a regra abaixo, descrita por LeCam (2009):

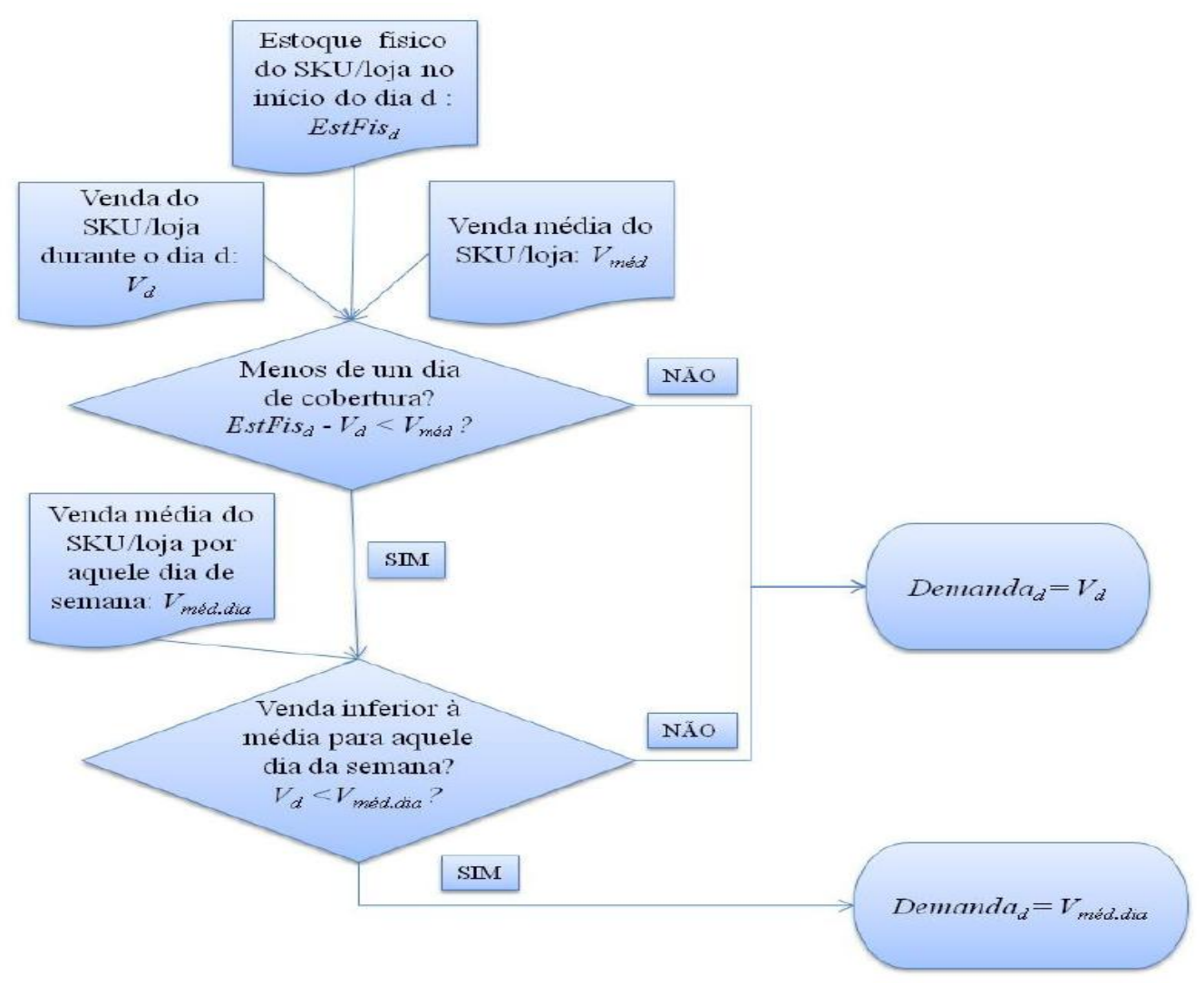

Figura 6.2 - Regra de correção das vendas com avaliação das faltas. Fonte: LeCam ( 2009) 
Basicamente, a regra descrita por LeCam (2009), utiliza a venda do dia d (Vd), o estoque físico do início do dia d (EstFisd), a venda média do SKU na loja (Vmed) e a venda média do SKU na loja por dia da semana (Vmed.dia).

Para identificar e corrigir pré-faltas ou perigos de ruptura, como descrito por LeCam (2009), é feita uma comparação entre a venda média e a cobertura (estoque fisico venda no dia), ou seja, se não houver cobertura de pelo menos um dia de venda, é possível que se trate de uma situação de pré-falta.

Caso a quantidade dessa pré-falta seja menor que a venda média para aquele dia da semana, tal valor é corrigido com a venda média do dia da semana (Vmed.dia). Caso contrário, não se tratará de uma pré-falta, e o valor da venda no dia $(\mathrm{Vd})$ será mantido.

\subsubsection{Picos de venda}

Cerca de 19,3\% da amostra apresentou variação típica de picos de venda. Tal situação deve-se à rotina existente nos varejos relacionada a atividades promocionais na loja, como tablóides (encartes promocionais oferecidos aos consumidor na entrada da loja), promoções em TV, distribuição de brindes ou mesmo rebaixamento de preço.

Tais atividades causam significativa variação nas vendas e, se não tratadas corretamente, podem acarretar leituras incorretas na previsão de demanda.

Para identificação e tratamento dos picos de venda, foi utilizada a venda média do dia da semana para comparação com a venda no dia. Caso o valor da venda do dia seja significativamente maior, o valor da venda do dia é corrigido (substituído) pela venda média do dia da semana. 


\subsubsection{Venda negativa, estoque negativo ou venda com estoque zerado}

Entre as situações encontradas, foram identificados e tratados também os casos de venda negativa (num total de $0,1 \%$ da amostra), cuja causa, após investigação, descobriu-se ter sido devolução de produtos e erros na entrada das quantidades de estoque no sistema.

Para esses casos, a regra aplicada foi substituir o valor de venda do dia da semana e extrair da quantidade do estoque, no dia anterior, o valor negativo para corrigir também os valores de estoque.

Para os casos de estoques negativos, que representaram cerca de $1 \%$ da amostra, foi identificado, através da investigação de causas, erro ou inversão das quantidades em sistema, o que normalmente ocorre durante o recebimento do produto na loja.

Para estes casos a, correção aplicada foi carregar, para estes valores de estoque, o estoque médio daquele dia da semana.

Cerca de 1,6\% da amostra concentrou-se na seguinte situação: num dado dia, houve venda, porém não havia estoque nem no dia anterior, nem no dia da venda; a investigação feita identificou como causa também os possíveis erros na inversão das quantidades de estoque em sistema, em virtude de erros durante o recebimento das mercadorias na loja.

Tais situações foram corrigidas utilizando como regra a substituição dos valores de estoque no dia atual e anterior pelo correspondente estoque médio do dia da semana.

As demais situações encontradas, somadas, representaram 0,0033\%, e, devido à sua pouca representatividade, não receberam nenhum tratamento específico para sua correção. 


\subsection{ANÁLISE DE PADRÕES DOS DADOS}

\subsubsection{Autocorrelogramas e padrões de dados}

A análise de padrões dos dados foi fundamentada na análise de autocorrelação das variáveis através dos autocorrelogramas já introduzido no item 3.2.4. Embora o SGE, software utilizado já desenvolva essa análise automaticamente, optou-se por efetuar uma pré-análise de maneira a confirmar os resultados obtidos pelo software.

Os autocorrelogramas, como já apresentados anteriormente, são uma ferramenta para sistematização do cálculo dos índices de autocorrelação e também demonstração gráfica dos mesmos, incluindo o intervalo de confiança.

Segundo Hanke e Reitsch (1998), sejam $Y_{t}$ e $Y_{t-1}$ observações dos dados no momento $\mathrm{t}$ e $\mathrm{t}-1$, os padrões de dados, incluindo tendência, sazonalidade e irregularidade, podem ser estudados usando a abordagem de autocorrelação da seguinte regra:

- Se a série é aleatória, a correlação entre $Y_{t}$ e $Y_{t-1}$ é próxima de zero, e os sucessivos valores da série no tempo não estão relacionados entre si.

- Se a série possui uma tendência, $Y_{t}$ e $Y_{t-1}$ são correlacionados, e os coeficientes de autocorrelação são significativamente diferentes de zero; o coeficiente de correlação para a defasagem 1 é tipicamente muito alto (próximo de 1), assim como a defasagem 2 que será alta, mas não tanto quanto a primeira - e assim por diante.

- Se a série possui um padrão sazonal, um coeficiente de autocorrelação significativo irá ocorrer na apropriada defasagem. Por exemplo: quatro para dados trimestrais, ou 12 para dados mensais. 


\subsubsection{Resultados da análise de autocorrelação}

Foram gerados os autocorrelogramas através do programa de computador Minitab® para cobrir as 50 combinações de SKU x loja, apresentandas na tabela abaixo:

Tabela 6.6 - Resumo da análise de autocorrelação para as combinações SKU x loja da amostra

\begin{tabular}{ccc}
\hline Padrão & $\begin{array}{c}\text { Número de ocorrências na } \\
\text { amostra }\end{array}$ & $\begin{array}{c}\text { de Representatividade } \\
\text { na amostra }\end{array}$ \\
\hline Tendência & 8 & $16 \%$ \\
Tendência e Sazonalidade & 22 & $44 \%$ \\
Sazonalidade & 20 & $40 \%$ \\
\hline
\end{tabular}

Como principais resultados da análise de autocorrelação, 84\% das combinações apresentaram algum padrão sazonalidade, 44\% tendência e sazonalidade e $8 \%$ somente tendência. Um exemplo de um dos autocorrelogramas analisados pode ser visto na figura 6.3:

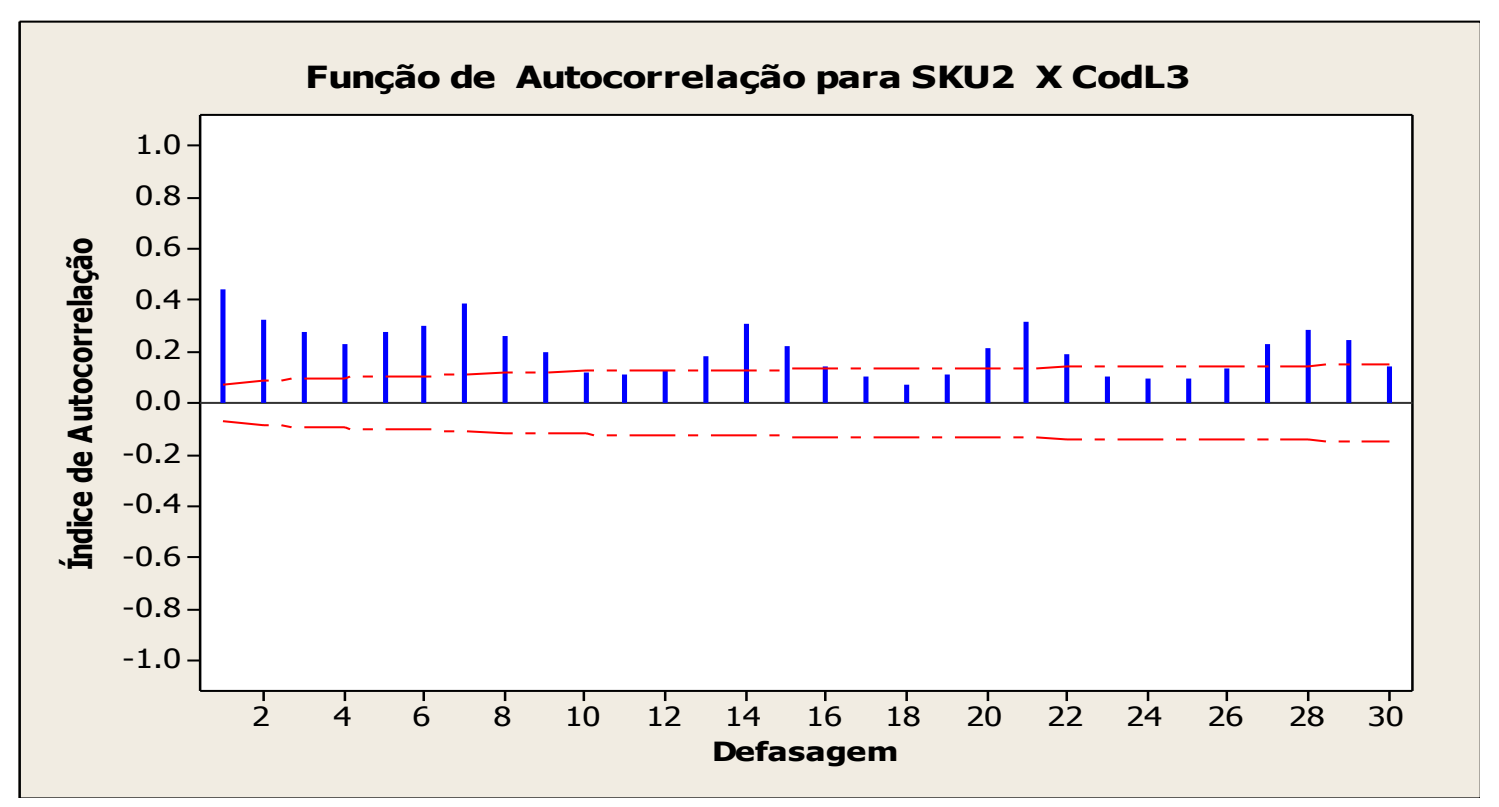

Figura 6.3 - Autocorrelograma para SKU2 na Loja3

As sazonalidades encontradas foram analisadas separadamente, e concluiu-se que, para esse conjunto de combinações, havia alto padrão de sazonalidade semanal. 
Através da análise gráfica foi possível confirmar aumento de vendas durante os finais de semana, o que, csegundo o Varejo, é um padrão esperado no segmento de supermercados, uma vez que a maior parte de seus clientes possui maior disponibilidade de tempo para compras no final de semana.

Não foram identificadas sazonalidades dezenais significativas nesta amostra.

Apesar do SGE efetuar estes cálculos automaticamente, essa análise teve por objetivo validar a escolha dos modelos pelo software, o que poderá ser visto na seção 5 , adiante.

Com base nestes resultados, e considerando a relação entre o padrão da série histórica e a técnica mais adequada para previsão, foram identificadas as seguintes técnicas como mais adequadas para serem utilizadas na validação do modelo de projeção, de forma a cobrir os padrões de tendência e sazonalidade da amostra: Suavização exponencial, suavização exponencial ajustada para tendência ou método de Holt e suavização exponencial ajustada para tendência e sazonalidade ou método de Holt-Winter.

\subsection{MODELO DE GESTÃO DE ESTOQUES}

\subsubsection{Indicadores de desempenho}

Considerando o objetivo do modelo de decisão "Minimizar os custos operacionais e de e de estoque (do Varejo) tendo como restrição um nível mínimo de serviço ao cliente", foram definidos como principais indicadores: 
6.4.1.1 Fill Rate (Nível de atendimento aos pedidos)

Diz respeito ao percentual de atendimento da demanda (em nossa amostra, representada pelas vendas extraídas do sistema do Varejo pós-tratamento de dados). Trata-se do indicador que mais está relacionado ao tema das rupturas e é calculado da seguinte maneira:

$$
\text { FillRate }=\frac{\sum_{i=1}^{n} \text { VendasEfet uadas }}{\sum_{i=1}^{n} \text { DemandaTotal }}
$$

Onde $\mathrm{n}$ é a quantidade de períodos (dias) de avaliação, Vendas Efetuadas diz respeito às vendas que ocorreram de fato sem atraso ou falta de estoque, e Demanda Total trata do total solicitado (pedido) independentemente de atraso ou falta.

\subsubsection{Custo operacional}

Para fins de simplificação, os principais custos selecionados como indicadores foram os custos de pedido, relacionados à elaboração e transmissão dos pedidos e custos de armazenagem e movimentação dos estoques.

Não foram considerados os custos de transportes em virtude de não variação dos custos com relação à quantidade ou tamanho dos pedidos. 


\subsubsection{O modelo atual de gestão de estoques do Varejo}

O modelo de estoque atualmente executado nas lojas do Varejo pode ser classificado como ativo. A previsão é baseada na mediana das últimas 13 semanas, regra esta estabelecida pelos tomadores de decisão da área de abastecimento.

O período de revisão é de um dia, e os pedidos são emitidos diariamente para todos os SKUs e todas as lojas, todos os dias da semana a partir da necessidade líquida calculada no momento da revisão, considerando $\mathrm{T}$ a soma entre o lead time e o período de revisão conforme apresentado a seguir:

Ordem de Compra = Previsão $(\mathrm{T})$ - Estoque físico atual - Estoque em trânsito + Estoque de Segurança

O estoque de segurança não segue nenhum tipo de algorítmo matemático para seu cálculo. Este parâmetro é manipulado manualmente pelos gestores de abastecimento, de forma a garantir o cumprimento dos objetivos de redução de estoque definidos pela Diretoria do Varejo. O sistema atual funciona sob a plataforma SAP.

\subsubsection{Parametrização do módulo}

Como já foi introduzido, o módulo de busca, simulação e comparação, demonstrado na figura 6.1, permite comparar modelos ativos e reativos de estoque, assim como os modelos de previsão, de diversas formas e com imposição de restrições e limitantes que envolvem mais de 170 parâmetros de entrada.

Embora vários destes necessitem de definição para que o software execute corretamente as comparações, nem todos são obrigatórios (Freire, 2007). 
O tempo de espera constante, a fração defeituosa nula e a capacidade de oferta de itens infinita eliminam a variação dos níveis de estoque provocada por reposição deste (Freire, 2007).

Os efeitos destas variações se confundem com as de demanda. Esta simplificação ajuda a analisar o desempenho dos modelos com base nas suas regras de funcionamento, sem a interferência destas variações nos custos de falta e armazenamento (Freire, 2007).

O nível de atendimento é um dos parâmetros do sistema e desta pesquisa, sendo, portanto, um dado solicitado pelo sistema.

O preço unitário do item necessita ser informado pelo fato do módulo calcular o custo de armazenagem como um percentual desse preço (a taxa de armazenagem). O preço é mantido inalterado durante todo o processo de simulação, sendo a taxa uma das entradas do vetor de dados de custo e tempo de espera (Freire, 2007).

\subsubsection{Rotina de busca e simulação para modelos de previsão}

A rotina de busca e simulação, descrita por Freire (2007), se baseia nos métodos de suavização descritos na figura 6.7 e utiliza a sequência lógica, conforme demonstrado na figura 6.1 e detalhada abaixo: 
Tabela 6.7 - Métodos de suavização e seus parâmetros

\begin{tabular}{|c|c|c|c|c|}
\hline Modelo & Hipótese & $\begin{array}{l}\text { Parâmetros } \\
\text { de } \\
\text { suavização }\end{array}$ & Equação de Suavização & Equação de Projeção \\
\hline $\begin{array}{c}\text { Suavização } \\
\text { Exponecial } \\
\text { simples }\end{array}$ & $\begin{array}{c}\text { Série } \\
\text { estacionária }\end{array}$ & $\alpha$ & $\hat{Y}_{t+1}=\alpha Y_{t}+(1-\alpha) Y_{t}$ & $\hat{Y}_{t+p}=\hat{Y}_{t+1}$ \\
\hline $\begin{array}{l}\text { Modelo de } \\
\text { Holt }\end{array}$ & $\begin{array}{l}\text { Série com } \\
\text { tendência }\end{array}$ & $\alpha \in \beta$ & $\begin{array}{l}A_{t}=\alpha Y_{t}+(1-\alpha)\left(A_{t-1}+T_{t-1}\right) \\
T_{t}=\beta\left(A_{t}+A_{t-1}\right)+(1-\beta) T_{t-1}\end{array}$ & $\hat{Y}_{t+p}=A_{t}+p T_{t}$ \\
\hline $\begin{array}{l}\text { Modelo de } \\
\text { Winters para } \\
\text { série } \\
\text { estacionária }\end{array}$ & $\begin{array}{l}\text { Série } \\
\text { estacionária } \\
\text { com } \\
\text { sazonalidade }\end{array}$ & $\alpha \in \gamma$ & $\begin{array}{l}A_{t}=\alpha \frac{Y_{t}}{S_{t-L}}+(1-\alpha)\left(A_{t-1}\right) \\
S_{t}=\gamma \frac{Y_{t}}{A_{t}}+(1-\gamma) S_{t-L}\end{array}$ & $\hat{Y}_{t+p}=A_{t} S_{t-L+p}$ \\
\hline $\begin{array}{l}\text { Modelo de } \\
\text { Winters }\end{array}$ & $\begin{array}{l}\text { Série com } \\
\text { tendência e } \\
\text { sazonalidade }\end{array}$ & $\alpha, \beta$ e $\gamma$ & $\begin{array}{l}A_{t}=\alpha \frac{Y_{t}}{S_{t-L}}+(1-\alpha)\left(A_{t-1}+T_{t-1}\right) \\
T_{t}=\beta\left(A_{t}+A_{t-1}\right)+(1-\beta) T_{t-1} \\
S_{t}=\gamma \frac{Y_{t}}{A_{t}}+(1-\gamma) S_{t-L} \\
.\end{array}$ & $\hat{Y}_{t+p}=\left(A_{t}+p T_{t}\right) S_{t-L+p}$ \\
\hline
\end{tabular}

\section{Fonte: Freire (2007)}

1) Para cada item, modelo e projeção, são calculados os valores iniciais de $\mathrm{A} e$ $T$ das fórmulas de suavização, utilizando no exemplo de aplicação os primeiros 24 períodos da série como o período de inicialização. Para isso, funções disponíveis no VBA são usadas de acordo com cada modelo:

- Suavização exponencial simples - Média aritmética dos períodos 1 a 24

- Modelo de Holt para tendência - Regressão linear simples dos períodos de 1 a 24

- Modelos de Winters (estacionária com sazonalidade) - Média aritmética dos períodos de 1 a 24

- Modelo de Holt Winters (tendência e sazonalidade) - Regressão linear simples dos períodos 1 a 24

2) $O$ valor da reta de regressão no final do período 24 é utilizado como o valor inicial de A24. O valor de A0 (valor da reta no instante zero ou no início do período 1) também é calculado para a utilização na rotina de modelos de estoque. A inclinação da mesma reta é o valor inicial adotado para o 
incremento de T24. Para os modelos de suavização exponencial simples e Winters (séries estacionárias) o valor adotado de A24 é a média aritmética. Nestes modelos, como visto anteriormente, não existe o parâmetro T. O vetor de sazonalidade da série fornecido no conjunto de dados de demanda, é adotado como o vetor inicial da sazonalidade.

3) Nessa fase da validação, os valores iniciais de $\alpha, \beta$ e $\gamma$ são 0,5 , centro das faixas de valores informada na parametrização do módulo $(0$ a 1 neste trabalho).

4) Os valores de $A, T$ ou $S$ do primeiro modelo são calculados, período a período, pelos restantes no exemplo de aplicação. Os desvios de projeção também são calculados período a período, e o MAD ao final da validação é adotado como medida de desempenho do modelo para os valores correntes de $\alpha, \beta$ ou $\gamma$.

5) Novos valores de $\alpha, \beta$ ou $\gamma$ são calculados pela sub-rotina de busca, repetindo-se a sequência de 2 a 4 até que a parada das iterações ocorra, devido a um dos critérios de parada. Os valores de $\alpha, \beta$ ou $\gamma$ correspondentes ao menor MAD obtido para o modelo são adotados como os valores ótimos de cada modelo.

6) O próximo modelo de previsão é carregado, e a sequência de 2 a 4 repetida até a a nova parada e até que o último modelo de previsão seja otimizado.

7) Ao final do processo, são comparados os valores de MAD correspondentes aos ótimos de $\alpha, \beta$ ou $\gamma$ de cada modelo. O modelo de menor MAD é selecionado para uso com o modelo ativo de estoque, e os valores de A0, T0, $\alpha, \beta$ e $\gamma$ correspondentes, transferidos para a rotina dos modelos de estoque.

Segundo Freire (2007), o caminho percorrido e a vizinhança testada são guardados para que se evitem loops. Vários critérios de parada são utilizados para o encerramento da sub-rotina. Os principais são: 
- Quantidade máxima de iterações $=800$

- Quantidade máxima de iterações seguidas sem redução do MAD = 70

- Tempo máximo de busca $=20 \mathrm{~s}$

Os passos utilizados são $0,05 \%, 0,02 \%$ e $0,01 \%$ do valor da semente do parâmetro, iniciando-se pelo maior e mudando-se para o menor seguinte - da forma já explicada.

No modelo de previsão de Winters com hipótese de tendência e sazonalidade, no qual os 3 parâmetros precisam ser otimizados em conjunto, a sequência de mudança de parâmetro é $\alpha$, depois $\beta$, em seguida $\gamma$, novamente $\alpha$, e assim por diante.

É importante destacar que, a rotina identifica os melhores parâmetros para a demanda fornecida num dado espaço de tempo, mantendo estes parâmetros até que seja necessário executar a rotina novamente. Esta situação pode trazer desvantagens aos modelos reativos versus os modelos ativos, uma vez que tais parâmetros não se atualizam dinamicamente.

\subsubsection{Rotina de busca e simulação para modelos de estoque}

Nesta segunda rotina, os modelos de estoque são simulados de forma a se estabelecer, para cada modelo, os valores dos seus parâmetros que minimizam o custo de operação restritos ao nível mínimo de atendimento imposto, conforme descrito por Freire (2007).

A rotina calcula, inicialmente, as previsões de demanda para o modelo de CALNEC. Para isto, utiliza as equações do modelo de previsão selecionado na rotina anterior, os parâmetros $\alpha, \beta$ ou $\gamma$ ótimos encontrados. 
As equações são aplicadas a partir do primeiro período da série do item, o que torna necessário o conhecimento de A0, T0 e do vetor S para o cálculo (Freire, 2007).

Em seguida, são calculados os valores iniciais dos parâmetros de cada modelo que serão utilizados como as sementes da busca. São utilizados cálculos tradicionais, indicados na tabela 6.8. Importante ressaltar que, embora presente no sistema o parâmetro necessidade líquida mínima não foi utilizado neste pesquisa.

Tabela 6.8 - Referência de cálculo para valores iniciais de parâmetros

\begin{tabular}{|c|c|}
\hline Parâmetro & Referência de Cálculo \\
\hline Ponto de Pedido & $\begin{array}{l}\text { Demanda média no tempo de espera } \\
\text { somada ao estoque de segurança }\end{array}$ \\
\hline Estoque máximo / Estoque base & $\begin{array}{l}\text { Valor correspondente ao nível de } \\
\text { atendimento }(60 \%) \text { na distribuição normal } \\
\text { formada a partir das demandas da série }\end{array}$ \\
\hline Lote fixo & Lote Econômico (LEC) \\
\hline & $\begin{array}{l}\text { Modelos reativos: Diferença entre estoque } \\
\text { máximo e a demanda média real da série }\end{array}$ \\
\hline Estoque de segurança & $\begin{array}{l}\text { Modelo ativo: Valor correspondente ao } \\
\text { nível de atendimento }(60 \% \text { quando o } \\
\text { parâmetro não é pré-fixado, inicia-se por } \\
\text { este valor) }\end{array}$ \\
\hline Necessidade líquida mínima & Lote Econômico (LEC) \\
\hline
\end{tabular}

Fonte: Freire (2007)

A simulação é, então, efetuada para cada um dos sete modelos de estoque. Ao final de cada período, é calculado o estoque após a respectiva demanda e executa-se a regra de decisão de reposição de estoque.

Ao final do último período de simulação, a quantidade média de pedidos, a média das faltas e o estoque médio por período são calculados. Períodos iniciais e finais que não são afetados pelas decisões do modelo são desprezados no cálculo dos custos.

Os custos médios por período de pedido, armazenagem e falta são calculados, aplicando-se os custos unitários fornecidos pelo vetor de dados de custo e tempo de espera. 
O custo de operação final de cada modelo, correspondente à soma destes três custos médios (em nossa pesquisa, dois), é utilizado como medida de desempenho (Freire, 2007).

O mecanismo de busca dos valores ótimos é semelhante ao utilizado na rotina anterior, ilustrada na figura 4.5 , com os modelos de estoque no lugar dos modelos de previsão, $\alpha$ e $\beta$ substituídos pelos respectivos parâmetros de cada modelo e a medida do desempenho do custo de operação substituindo o MAD.

Após a simulação de todos os itens do conjunto de dados de demanda e a definição dos valores ótimos, é feita a classificação dos modelos de estoque, item a item, segundo ordem crescente dos seus custos de operação, agrupados em um relatório de saída, como pode ser visto na tabela 6.9 abaixo.

Tabela 6.9 - Exemplo de relatório de saída do SGE

\begin{tabular}{|c|c|c|c|c|c|c|c|c|c|c|c|c|}
\hline CODSKU & CODTOTAL & Codttem & CodModEst & it Clasflv & odEst Pa & & ParE2 & NivAtdBoa & EstMedPerVal & CtoPedPerVal & CtoArmPerVal & CustoTotal \\
\hline$\overline{\text { SKU1 }}$ & SKU1LOJA1 & 1 & & 4 & 2 & 132.7 & 204.7 & 0.952 & 454.410 & 0.049 & 3.181 & 3.230 \\
\hline SKU1 & SKU1LOJA1 & 1 & & 5 & 4 & 24 & 181.1 & 0.954 & 457.330 & 0.130 & 3.201 & 3.331 \\
\hline SKU1 & SKU1LOJA1 & 1 & & 6 & 3 & 146 & 48 & 0.952 & 454.299 & 0.074 & 3.180 & 3.254 \\
\hline SKU1 & SKU1LOJA1 & 1 & & 7 & 1 & 24 & 92 & 0.950 & 364.398 & 0.128 & 2.551 & 2.678 \\
\hline SKU1 & SKU1LOJA1 & 1 & & 8 & 5 & 190 & & 0.953 & 480.330 & 0.772 & 4.166 & 4.938 \\
\hline SKU1 & SKU1LOJA2 & 2 & & 4 & 5 & 47.7 & 71.7 & 0.953 & 128.856 & 0.086 & 1.902 & 1.988 \\
\hline SKU1 & SKU1LOJA2 & 2 & & 5 & 2 & 24 & 71.8 & 0.953 & 128.856 & 0.075 & 0.924 & 0.999 \\
\hline SKU1 & SKU1LOJA2 & 2 & & 6 & 1 & 48.2 & 24 & 0.953 & 128.856 & 0.096 & 0.902 & 0.997 \\
\hline SKU1 & SKU1LOJA2 & 2 & & 7 & 3 & 24 & 29.2 & 0.954 & 135.316 & 0.076 & 0.947 & 1.023 \\
\hline SKU1 & SKU1LOJA2 & 2 & & 8 & 4 & 51 & & 0.956 & 132.086 & 0.756 & 0.962 & 1.718 \\
\hline
\end{tabular}




\section{DISCUSSÃO DOS RESULTADOS}

Uma vez parametrizado o SGE (Sistema de Gestão de Estoques), com os custos de pedido de $R \$ 0,41$, taxa de armazenamento de 0,007 e nível de serviço mínimo de 0,95 , o resultado da primeira execução que demonstra o percentual de sucesso de cada modelo em termos de $1^{\circ}, 2^{\circ}, 3^{\circ}, 4^{\circ}$, e $5^{\circ}$ lugar pode ser visto na tabela abaixo.

Tabela 7.1 - Resultado consolidado do desempenho dos modelos de reposição de estoque por \% de cada um dentre cada classificação

\begin{tabular}{cccccc}
\hline Modelos de Reposição & 10. & 20. & 30. & 40. & 50. \\
\hline RepMaxC & $10 \%$ & $26 \%$ & $32 \%$ & $18 \%$ & $14 \%$ \\
RepBasC & $2 \%$ & $32 \%$ & $24 \%$ & $42 \%$ & $0 \%$ \\
LotFixC & $8 \%$ & $24 \%$ & $36 \%$ & $26 \%$ & $6 \%$ \\
CalNec & $80 \%$ & $10 \%$ & $6 \%$ & $2 \%$ & $2 \%$ \\
ModAtual & $0 \%$ & $8 \%$ & $2 \%$ & $12 \%$ & $78 \%$ \\
\hline
\end{tabular}

Para a amostra estudada, o modelo de cálculo das necessidades apresentou o melhor desempenho em $80 \%$ das combinações SKU x loja. Isso era de certa forma esperado, uma vez que a análise de autocorrelação dos dados demonstrou alto percentual de sazonalidade em $84 \%$ da amostra, como visto no item 4.3.2.

Como pode ser visto na tabela 7.2 abaixo, $88 \%$ da amostra de SKU x loja apresentou melhor desempenho através de modelos que lidam com sazonalidade como um de seus componentes.

O segundo melhor modelo, vencedor em $32 \%$ da amostra, foi o de reposição pelo máximo continuo. O modelo de reposição pela base ficou em $3^{\circ}$, o de lote fixo contínuo em $4^{\circ}$ lugar e, por último, o modelo atualmente utilizado pelo Varejo, que, como já explicado, trata-se de um modelo ativo. 
Tal posicionamento do modelo atual não era esperado nos resultados, o que veio a confirmar o alto nível de impacto do erro de previsão no desempenho do modelo de estoque e/ou parametrização do modelo atual.

Tabela 7.2 - Resultado consolidado dos modelos de projeção por SKU

\begin{tabular}{lcccccc}
\hline \multicolumn{1}{c}{ Modelos de Projeção } & SKU1 & SKU2 & SKU3 & SKU4 & SKU5 & Média \\
\hline Suavização exponencial constante & $20 \%$ & $0 \%$ & $0 \%$ & $10 \%$ & $0 \%$ & $6 \%$ \\
Suavização exponencial com tendência & $20 \%$ & $0 \%$ & $0 \%$ & $0 \%$ & $10 \%$ & $6 \%$ \\
Suavização exponencial simples com sazonalidade & $20 \%$ & $60 \%$ & $60 \%$ & $50 \%$ & $40 \%$ & $46 \%$ \\
Suavização exponencial com tendência e sazonalidar & $40 \%$ & $40 \%$ & $40 \%$ & $40 \%$ & $50 \%$ & $42 \%$ \\
\hline
\end{tabular}

Com relação aos custos, como pode ser visto na tabela 7.3, que descreve o custo do total dos itens de cada modelo por classificação atingida, da melhor, iniciando-se por 1 (um), até a pior, 5 (cinco), a economia média entre o custo atual $(135,8)$ e os demais foi da ordem de $27 \%$, considerando todas as configurações com exceção da última (5) que não apresenta economia.

A melhor configuração (conjunto dos melhores desempenhos de todos os modelos) oferece uma economia de até $42 \%$ frente ao custo atual e também é $18 \%$ melhor que a $2^{\underline{a}}$ configuração.

Isso só reforça o fato de que acertar o modelo adequado para cada item poderá trazer ganhos consideráveis em relação, não só à pior configuração, como também ao modelo atualmente implementado.

Outro ponto observado foi o fato do modelo atual apresentar um desempenho pior mesmo comparado às configurações não vencedoras ( $2^{\circ}, 3^{\circ}$ e $4^{\circ}$ lugares), que apresentaram resultados, no mínimo, 13\% superiores com relação ao custo do modelo atual.

Importante ressaltar que os modelos reativos apresentaram desempenho muito próximo do ponto de vista de custo total por modelo. 
Tabela 7.3 - Resultado detalhado dos custos de cada modelo por classificação

\begin{tabular}{rrrrrrrc}
\hline Modelo de Reposição & 10. & 20. & \multicolumn{1}{c}{ 30. } & \multicolumn{1}{c}{ 40. } & 50. & $\begin{array}{c}\text { Custo } \\
\text { Total por } \\
\text { modelo }\end{array}$ & $\begin{array}{c}\text { Economia se } \\
\text { aplicado somente } \\
\text { um modelo }\end{array}$ \\
\hline RepMaxC & 7.8 & 28.5 & 39.7 & 17.3 & 19.1 & 112.4 & $17 \%$ \\
RepBasC & 1.3 & 32.9 & 29.7 & 46.0 & & 110.0 & $19 \%$ \\
LotFixC & 3.7 & 11.2 & 31.7 & 39.6 & 21.1 & 107.3 & $21 \%$ \\
CalNec & 65.4 & 6.7 & 2.9 & 1.4 & 3.1 & 79.5 & $41 \%$ \\
ModAtual & & 16.2 & 3.0 & 13.7 & 103.0 & 135.8 & \\
\hline Custo total por configuração & 78.3 & 95.5 & 107.0 & 118.1 & 146.2 & & \\
Economia x Configuração Atual & $42 \%$ & $30 \%$ & $21 \%$ & $13 \%$ & $-8 \%$ & & \\
\hline
\end{tabular}

Outra possível comparação tem seus resultados demonstrados na última coluna da mesma tabela acima. Suponha que, para fins de simplificação, aplicássemos somente um modelo para todas as combinações SKU x loja.

Para este caso, a economia média entre todos os modelos seria ainda de $25 \%$, sendo o melhor desempenho conseguido através do modelo de cálculo das necessidades $(41 \%)$, e o pior conseguido pela reposição pelo máximo contínuo, e ainda assim apresentando economia de $17 \%$ versus o modelo atual.

Esse exercício tem como principal fundamento o fato de um varejo, de forma a reduzir a complexidade de manutenção de seus sistemas de reposição, eleger em um dado momento um único modelo em seus sistemas de reabastecimento que mais se adapte à maioria dos SKUs.

Do ponto de vista de SKU x loja, como consta na tabela 7.4, o modelo Calnec foi o vencedor em $100 \%$ dos SKUs, tendo apresentado como melhor modelo, a representatividade de $90 \%$ nos SKUs 3, 4 e 5, 70\% no SKU 2 e $50 \%$ no SKU 1.

Este último foi o mais heterogêneo em relação à composição dos modelos vencedores entre todas as suas configurações SKU x lojas, apresentando o modelo de reposição pelo máximo como $2^{\circ}$ maior vencedor. 
Esta situação ocorre pelo fato deste SKU apresentar uma demanda predominantemente estável em 50\% das lojas, sem alterações significativas (crescentes ou decrescentes) ao longo do tempo analisado.

Tabela 7.4 - Percentual do modelo vencedor por SKU x loja

\begin{tabular}{ccccccc}
\hline Modelo de Reposição & SKU1 & SKU2 & SKU3 & SKU4 & SKU5 & Média \\
\hline RepMaxC & $30 \%$ & $10 \%$ & $0 \%$ & $10 \%$ & $0 \%$ & $10 \%$ \\
RepBasC & $0 \%$ & $10 \%$ & $0 \%$ & $0 \%$ & $0 \%$ & $2 \%$ \\
LotFixC & $20 \%$ & $10 \%$ & $10 \%$ & $0 \%$ & $0 \%$ & $8 \%$ \\
CalNec & $50 \%$ & $70 \%$ & $90 \%$ & $90 \%$ & $100 \%$ & $80 \%$ \\
ModAtual & $0 \%$ & $0 \%$ & $0 \%$ & $0 \%$ & $0 \%$ & $0 \%$ \\
\hline
\end{tabular}

Com relação a custos, como mostra a tabela abaixo, que detalha os custos dos modelos vencedores por SKU comparados ao modelo atualmente utilizado pelo Varejo, os SKUs 3 e 4 foram os que apresentaram maior economia em relação ao modelo atual, respectivamente $58 \%$ e $64 \%$ menor em termos econômicos.

Tais SKUs, como pode ser visto na seção 4.1, são classificados como SKUs de baixo volume, o que, segundo a literatura, torna mais difícil a precisão de uma previsão. Este resultado demonstra que de fato o erro de previsão do modelo atual era significativamente maior nesse tipo de SKU.

Situação contrária pode ser vista nos SKUs 1, 5 e 2 - respectivamente, alto (1 e 5) e médio volume (2) -, que apresentaram menor diferença percentual entre o custo do modelo atual e o do melhor modelo.

Isto pode ter sido causado pela razão diretamente oposta à dos SKUs de baixo volume; nestes, a previsão provavelmente era um pouco mais precisa por se tratar de um volume maior de demanda. 
Tabela 7.5 - Resultado detalhado dos custos dos modelos vencedores por SKU

\begin{tabular}{rccccc}
\hline & SKU1 & SKU2 & SKU3 & SKU4 & SKU5 \\
\hline RepMaxC & 6.2 & 1.2 & & 0.4 & \\
RepBasC & & 1.3 & & & \\
LotFixC & 2.0 & 1.3 & 0.4 & & \\
CalNec & 14.2 & 12.7 & 4.2 & 5.7 & 28.6 \\
Custo total por sku (melhor configuração) & 22.4 & 16.6 & 4.6 & 6.1 & 28.6 \\
\hline ModAtual & 34.7 & 27.0 & 11.1 & 17.1 & 45.9 \\
Economia x ModAtual & $35 \%$ & $39 \%$ & $58 \%$ & $64 \%$ & $38 \%$ \\
\hline
\end{tabular}

A análise por loja reflete basicamente as situações identificadas na análise de SKUs. O modelo vencedor foi o modelo Calnec em $100 \%$ das lojas (tabela 7.6), em percentuais variados, como consequência da composição dos distintos SKUs.

Embora tenha sido verificada a redução de custo em diferentes graus em todas as lojas comparado ao modelo atualmente utilizado, não foi identificada nenhuma relação direta entre o volume da loja (conforme classificação na seção 4.1) e o percentual de redução de custo atingido, como consta na tabela 7.7.

Tabela 7.6 - Percentual do modelo vencedor por loja

\begin{tabular}{cccccccccccc}
\hline Modelo de Reposição & LOJA1 & LOJA2 & LOJA3 & LOJA4 & LOJA5 & LOJA6 & LOJA7 & LOJA8 & LOJA9 & LOJA10 & Média \\
\hline RepMaxC & $0 \%$ & $20 \%$ & $0 \%$ & $20 \%$ & $20 \%$ & $20 \%$ & $20 \%$ & $0 \%$ & $0 \%$ & $0 \%$ & $10 \%$ \\
RepBasC & $0 \%$ & $0 \%$ & $0 \%$ & $0 \%$ & $20 \%$ & $0 \%$ & $0 \%$ & $0 \%$ & $0 \%$ & $0 \%$ & $2 \%$ \\
LotFixC & $0 \%$ & $20 \%$ & $20 \%$ & $20 \%$ & $20 \%$ & $0 \%$ & $0 \%$ & $0 \%$ & $0 \%$ & $0 \%$ & $8 \%$ \\
CalNec & $100 \%$ & $60 \%$ & $80 \%$ & $60 \%$ & $40 \%$ & $80 \%$ & $80 \%$ & $100 \%$ & $100 \%$ & $100 \%$ & $80 \%$ \\
ModAtual & $0 \%$ & $0 \%$ & $0 \%$ & $0 \%$ & $0 \%$ & $0 \%$ & $0 \%$ & $0 \%$ & $0 \%$ & $0 \%$ & $0 \%$ \\
\hline
\end{tabular}

Tabela 7.7 - Resultado detalhado dos custos dos modelos vencedores por loja

\begin{tabular}{rcccccccccc}
\hline Modelos de Reposição & LOJA1 & LOJA2 & LOJA3 & LOJA4 & LOJA5 & LOJA6 & LOJA7 & LOJA8 & LOJA9 & LOJA10 \\
\hline RepMaxC & 1.2 & & 2.5 & 2.2 & 0.4 & 1.5 & & & \\
RepBasC & & & & & 1.3 & & & & & \\
LotFixC & & 1.0 & 1.0 & 1.3 & 0.4 & & & & \\
CalNec & 8.2 & 4.6 & 4.2 & 3.3 & 6.8 & 7.8 & 6.7 & 11.9 & 5.0 & 6.9 \\
Custo total por loja (melhor configuração) & 8.2 & 6.8 & 5.2 & 7.2 & 10.8 & 8.2 & 8.2 & 11.9 & 5.0 & 6.9 \\
\hline ModAtual & 15.2 & 12.3 & 11.0 & 10.8 & 20.3 & 13.2 & 14.1 & 18.3 & 9.1 & 11.6 \\
Economia x ModAtual & $46 \%$ & $45 \%$ & $53 \%$ & $34 \%$ & $47 \%$ & $38 \%$ & $42 \%$ & $35 \%$ & $45 \%$ & $40 \%$ \\
\hline
\end{tabular}


A análise de sensibilidade relativa ao nível de serviço simulou os resultados para fill rate mínimo de $89 \%$, 92\% e 98\%, de forma a entender a dinâmica entre diferentes níveis de serviço e seus respectivos impactos em custos.

Tal análise considerou também os resultados da primeira execução parametrizada em $95 \%$ de fill rate. Os custos de pedidos e de armazenagem não sofreram alterações nas quatro execuções.

Como era esperado, houve aumento significativo em todos os custos à medida que o fill rate também aumentava a cada uma das etapas. Observou-se que o percentual entre o custo da melhor configuração entre cada fill rate e o seguinte (que apresentava 3 pontos percentuais de diferença entre cada parâmetro) aumentou de forma desproporcional.

A primeira etapa, entre o fill rate $89 \%$ e $92 \%$, apresentou $11 \%$ de aumento de custo na melhor configuração; a segunda, entre 92\% e 95\%, apresentou 17\%; e a última, entre $95 \%$ e $98 \%$, apresentou $24 \%$ de aumento - todos coerentes com a teoria existente na literatura pesquisada.

Em todas as variações de nível de serviço, o modelo atual foi o último colocado. $O$ modelo de cálculo das necessidades apresentou o melhor desempenho com significativa vantagem em todas as simulações (vencedor, na média, em $82 \%$ das combinações SKU x loja), como pode ser visto na tabela 7.8.

A economia média entre o melhor e o pior modelo foi de $46 \%$. Para esta simulação, o modelo de reposição pela base ocupou o $2^{\circ}$ lugar na maior parte das execuções (em 2 de 3).

Embora o modelo de reposição pela base tenha apresentado maior frequência como $2^{\circ}$ melhor modelo, do ponto de vista de custo, os modelos de reposição pela base e reposição pelo máximo demonstraram resultados tecnicamente idênticos nas execuções de 0,89 , 0,92 e 0,98, como pode ser visto na tabela 7.9 , que compara os custos totais por modelo. 
$\mathrm{Na}$ prática, assim como na análise da execução de fill rate de $95 \%$, todos os modelos reativos apresentaram desempenhos similares.

Tabela 7.8 - Resultados em \% de SKU x loja da análise de sensibilidade paradiferentes níveis de serviço classificados por modelo de reposição

\begin{tabular}{|c|c|c|c|c|c|c|}
\hline Fill Rate & Modelo de Estoque & 10. & 20. & 30. & 40. & 50. \\
\hline \multirow{5}{*}{$89 \%$} & RepMaxC & $4 \%$ & $20 \%$ & $42 \%$ & $34 \%$ & $0 \%$ \\
\hline & RepBasC & $2 \%$ & $34 \%$ & $40 \%$ & $24 \%$ & $0 \%$ \\
\hline & LotFixC & $12 \%$ & $38 \%$ & $16 \%$ & $28 \%$ & $6 \%$ \\
\hline & CalNec & $82 \%$ & $4 \%$ & $2 \%$ & $12 \%$ & $0 \%$ \\
\hline & ModAtual & $0 \%$ & $4 \%$ & $0 \%$ & $2 \%$ & $94 \%$ \\
\hline \multirow{5}{*}{$92 \%$} & RepMaxC & $4 \%$ & $36 \%$ & $35 \%$ & $24 \%$ & $0 \%$ \\
\hline & RepBasC & $10 \%$ & $30 \%$ & $39 \%$ & $20 \%$ & $0 \%$ \\
\hline & LotFixC & $0 \%$ & $27 \%$ & $22 \%$ & $43 \%$ & $8 \%$ \\
\hline & CalNec & $86 \%$ & $2 \%$ & $4 \%$ & $8 \%$ & $0 \%$ \\
\hline & ModAtual & $0 \%$ & $5 \%$ & $0 \%$ & $4 \%$ & $92 \%$ \\
\hline \multirow{5}{*}{$95 \%$} & RepMaxC & $10 \%$ & $26 \%$ & $32 \%$ & $18 \%$ & $14 \%$ \\
\hline & RepBasC & $2 \%$ & $32 \%$ & $24 \%$ & $42 \%$ & $0 \%$ \\
\hline & LotFixC & $8 \%$ & $24 \%$ & $36 \%$ & $26 \%$ & $6 \%$ \\
\hline & CalNec & $80 \%$ & $10 \%$ & $6 \%$ & $2 \%$ & $2 \%$ \\
\hline & ModAtual & $0 \%$ & $8 \%$ & $2 \%$ & $12 \%$ & $78 \%$ \\
\hline \multirow{5}{*}{$98 \%$} & RepMaxC & $6 \%$ & $16 \%$ & $45 \%$ & $30 \%$ & $2 \%$ \\
\hline & RepBasC & $4 \%$ & $36 \%$ & $43 \%$ & $15 \%$ & $0 \%$ \\
\hline & LotFixC & $8 \%$ & $34 \%$ & $9 \%$ & $43 \%$ & $8 \%$ \\
\hline & CalNec & $82 \%$ & $6 \%$ & $2 \%$ & $11 \%$ & $0 \%$ \\
\hline & ModAtual & $0 \%$ & $8 \%$ & $0 \%$ & $2 \%$ & $90 \%$ \\
\hline
\end{tabular}


Tabela 7.9 - Resultados em custos da análise de sensibilidade para diferentes níveis de serviço classificados por modelo de reposição

\begin{tabular}{|c|c|c|c|c|c|c|c|c|}
\hline Fill Rate & Modelo de Estoque & 10. & 20. & 30. & 40. & 50. & $\begin{array}{l}\text { Custo total } \\
\text { por modelo } \\
\text { de estoque }\end{array}$ & $\begin{array}{l}\text { Diferença x } \\
\text { Modelo atual }\end{array}$ \\
\hline \multirow{5}{*}{$89 \%$} & RepMaxC & 1.5 & 13.7 & 39.6 & 26.8 & & 81.6 & $33 \%$ \\
\hline & RepBasC & 2.5 & 32.5 & 26.5 & 20.1 & & 81.6 & $33 \%$ \\
\hline & LotFixC & 5.0 & 22.5 & 13.0 & 26.4 & 16.1 & 83.0 & $31 \%$ \\
\hline & CalNec & 51.0 & 2.1 & 2.6 & 4.7 & & 60.5 & $50 \%$ \\
\hline & ModAtual & & 7.4 & & 5.5 & 108.2 & 121.1 & \\
\hline \multicolumn{2}{|c|}{ Custo total por configuração $(89 \%)$} & 60.0 & 78.3 & 81.6 & 83.6 & 124.3 & & \\
\hline \multirow{5}{*}{$92 \%$} & RepMaxC & 0.7 & 33.9 & 31.8 & 24.1 & & 90.5 & $28 \%$ \\
\hline & RepBasC & 4.0 & 31.7 & 34.6 & 20.1 & & 90.4 & $28 \%$ \\
\hline & LotFixC & & 19.0 & 20.3 & 33.1 & 20.8 & 93.2 & $26 \%$ \\
\hline & CalNec & 62.2 & 0.3 & 2.2 & 2.5 & & 67.2 & $47 \%$ \\
\hline & ModAtual & & 13.2 & & 4.2 & 108.5 & 126.0 & \\
\hline \multicolumn{2}{|c|}{ Custo total por configuração $(92 \%)$} & 66.9 & 98.1 & 88.9 & 83.9 & 129.4 & & \\
\hline \multirow{5}{*}{$95 \%$} & RepMaxC & 7.8 & 28.5 & 39.7 & 17.3 & 19.1 & 112.4 & $17 \%$ \\
\hline & RepBasC & 1.3 & 32.9 & 29.7 & 46.0 & & 110.0 & $19 \%$ \\
\hline & LotFixC & 3.7 & 11.2 & 31.7 & 39.6 & 21.1 & 107.3 & $21 \%$ \\
\hline & CalNec & 65.4 & 6.7 & 2.9 & 1.4 & 3.1 & 79.5 & $41 \%$ \\
\hline & ModAtual & & 16.2 & 3.0 & 13.7 & 103.0 & 135.8 & \\
\hline \multicolumn{2}{|c|}{ Custo total por configuração (95\%) } & 78.3 & 95.5 & 107.0 & 118.1 & 146.2 & & \\
\hline \multirow{5}{*}{$98 \%$} & RepMaxC & 1.6 & 23.2 & 57.1 & 37.7 & 5.9 & 125.5 & $31 \%$ \\
\hline & RepBasC & 6.5 & 32.0 & 63.5 & 23.0 & & 125.1 & $31 \%$ \\
\hline & LotFixC & 6.5 & 31.7 & 10.2 & 48.9 & 30.2 & 127.5 & $30 \%$ \\
\hline & CalNec & 82.8 & 8.1 & 0.8 & 6.4 & & 98.0 & $46 \%$ \\
\hline & ModAtual & & 19.4 & & 5.5 & 156.2 & 181.0 & \\
\hline \multicolumn{2}{|c|}{ Custo total por configuração (98\%) } & 97.4 & 114.4 & 131.6 & 121.6 & 192.3 & & \\
\hline
\end{tabular}

Especificamente sobre a simulação do fill rate de $98 \%$, embora haja o aumento de custo em todos os cenários à medida que há aumento de nível de serviço, foi possível identificar que o percentual entre o custo da melhor configuração nesta simulação (98\%) e o custo gerado pelo modelo atual configurado para atingir $95 \%$ foi inferior em $28 \%$.

Ou seja, é possível aumentar o nível de serviço, reduzindo os custos comparativamente aos valores atuais.

Não foi identificada nenhuma relação direta entre o desempenho dos modelos por custo do SKU, uma vez que nesta amostra os custos estavam diretamente relacionados ao volume. 


\section{CONCLUSÕES}

O objetivo desse trabalho foi analisar a viabilidade de aplicação uma sistemática de gestão de estoques que permitisse a escolha e parametrização de modelos de decisão de reposição de itens.

Tal proposta deve ser usada junto ao Varejo a fim de auxiliá-los na redução dos desvios de previsão de demanda e parametrização adequada de seu sistema de abastecimento.

Os resultados discutidos na seção anterior demonstraram que, através do modelo de decisão presente no sistema SGE, foi possível identificar o melhor modelo para cada SKU x loja da amostra, respeitando as restrições e parâmetros estabelecidos pelo varejo de nível de serviço e custo operacional total.

Tais resultados demonstraram também que, dentre os modelos analisados, incluindo o modelo atual implementado neste Varejo, o modelo de cálculo das necessidades demonstrou significativa superioridade, independentemente das variações de SKU.

Isso porque, uma vez sendo um modelo ativo, demonstrou maior aderência à demanda na sua maioria de significativa sazonalidade.

O Calnec foi superior também em todas as variações possíveis, seja por SKU, loja, ou diferentes níveis de serviço, tendo os modelos reativos, em $2^{\circ}$ lugar, apresentado resultados similares entre si.

O modelo atual, na maior parte das vezes, apresentou o pior desempenho dentre todas as execuções e variações analisadas. Os resultados deste último, também um modelo ativo, estão relacionados ao alto erro de previsão e/ou parametrização fundamentos básicos desta classe de modelos. 
Além disso, foi possível concluir também que, do ponto de vista do varejo, com a finalidade de simplificação de seu processo de manutenção de um sistema de gestão de estoques, seria possível ainda, eleger o melhor modelo e aplicá-lo a todos os SKUs da amostra, alcançando, uma economia significativa.

Da mesma forma, o modelo também demonstrou que o Varejo poderia optar por aumentar a restrição de nível de serviço, utilizando-se do modelo mais adequado (neste caso calnec), e ainda assim apresentaria economia frente ao modelo atual.

Como próximos passos, tais resultados e parâmetros estão sendo compartilhados junto ao varejo para configuração de seu sistema de gestão de estoque, de forma a analisar uma aplicação prática. 


\section{REFERÊNCIAS BIBLIOGRÁFICAS}

ACNiesen, 2004. Disponível em <http://www.amcham.com.br/ download/informativo2004-10-20h_arquivo>. Acesso em: 15/06/2010.

ANDERSON, J. C. et al. Material requirement planning systems: The state of the art. Production and Inventory Management, v. 23, n. 4, p. 51-66, 1982.

BALLOU, R. H. Gerenciamento da cadeia de suprimentos/logística empresarial. Porto Alegre: Bookman, 2006.

BARANSCI, E. et al. A report of Research on Inventory Models. Engineering Costs and Production Economics, v.7, p. 127-136, 1983.

BERTRAND, J. W. M.; FRANSOO, J.C. Operations Management Research Methodologies Using Quantitative Modeling, International Journal of Operations \& Production Management, v.22, n. 2, p 241-264, 2002.

BILLINGTON, P. J. et al. Mathematical programming approaches to capacity constrained MRP systems: Review, formulation and problem reduction. Management Science, v. 29, no. 10, p. 1126-1141, 1983.

BORGES, V. M. N. Acoplamento de um modelo de previsão de demanda de água a um modelo simulador em tempo real - Um estudo de caso: Sistema adutor metropolitano de São Paulo, 232p. Tese - Escola Politécnica, Universidade de São Paulo, São Paulo, 2003.

BOWERSOX, D. J.; CLOSS, D.J.; COOPER, M.B. Gestão logística de cadeias de suprimentos. Porto Alegre: Bookman, 2006.

CAUCHICK MIGUEL, P. A. Metodologia de Pesquisa em engenharia de produção e gestão de operações. Rio de Janeiro: Elsevier, 2010.

CROSTON, J. E. Forecasting and stock control for intermittent demands. Operational Research Quarterly v.23, p. 289-303, 1972.

DE BODT, M.; VAN WASSENHOVE, L. Lot sizes and safety stocks in MRP: A case study. Production and Inventory Management, v. 24, n.1, p. 1-16, 1983.

DELURGIO, S. et al. Forecasting weekly outpatient demand at clinics within a large medical center. Production and Inventory Management Journal v. 45 , n. 2, p. 3546, 2009.

DIAS, G. P. P.; YOSHIZAKI, H. T. Y. Gestão de estoques numa cadeia de distribuição com sistema de reposição automática e ambiente colaborativo. Biblioteca da Escola Politécnica - USP. 2000. 
FILHO, M. G.; FERNANDES, F. C. F. A. Practical method to reduce nervousness and improve performance in MRP systems: Proposal, Implementation and Results. Production and Inventory Management Journal. v,45 n.2. p. 65-79, 2009.

FREIRE, G. Estudo comparativo de modelos de estoques num ambiente com previsibilidade variável de demanda, 2007, 105 p., Tese (Mestrado). Escola Politécnica, Universidade de São Paulo, São Paulo, 2007.

GIL, A. C. Como elaborar projetos de pesquisa. São Paulo: Atlas, 1991.

GILCHRIST, W. Statistical forecasting--The state of the art, Omega, v. 2, n. 6, p. 733-750, Dezembro 1974.

GRUEN, T. W.; CORSTEN, S. D.; BHRADWAJ, S. Retail Out-of-Stocks: A Worldwide Examination of Extent, Causes and Consumer Responses. Washington: GMI/FMI, 2002.

HANKE, J. E.; REITSCH, A. G. Business Forecasting. New Jersey: Prentice Hall, 1998.

HARRIS, F. W., How many parts make at once, Factory, the Magazine of Management, v. 10, n. 2, p. 135-136, 152, 1913.

HAYES, T. R. An inventory control system for the Colorado school of mines. Production and Inventory Management Journal, v.35, n.4, p. 50, 40. trimestre 1994.

HAX, C. A., CANDEA, D., Production and Inventory Management, New Jersey: Prentice-Hall International, 1984.

HOLT, C. C. Forecasting seasonals and trends by exponentially weighted moving averages, International Journal of Forecasting, v. 20, n. 1, p. 5-10, Jan/Mar 2004.

JUNIOR, E. P. L. Otimização de estoques em pequena empresa do varejo. REGES Revista Eletrônica de Gestão, Picos, v. 2, n. 1, p. 22-39, jan./abr. 2009.

LAMBERT, M. D.; LALONDE, J. B. "Inventory carrying costs", Management Accounting, p. 31-35, 1976.

LECAM, S. L. Modelo de Decisão de suprimento de bens de consumo perecíveis no varejo baseado na previsão de demanda. 2009. 109p. Trabalho de formatura (graduação). Escola Politécnica, Universidade de São Paulo, 2009.

LEVY, M.; WEITZ, B. A. Administração de Varejo. São Paulo: Atlas, 2000.

LEWIS, C. D. Short-term forecasting for stationary demand situations. Demand Forecasting and Inventory Control, Butterworth-Heinemann, Boston, p. 21-43, 1997. 
LUSTOSA, L. et al. Planejamento e Controle da produção. Rio de Janeiro: Elsevier, 2008.

MAKRIDAKIS, S.; WHEELWRIGHT, S. C. Forecasting - Methods and Applications. New York: Wiley, 1978.

MONTANHEIRO, W. J.; FERNANDES, L. A. Gestão de estoques de materiais em uma confecção. Socorro: Faculdade XV de Agosto, 2008.

NADDOR, E. Inventory Systems. New York: John Wiley \& Sons, 1966.

PRASAD, S. Classification of Inventory Models and Systems. International Journal of Production Economics, v.34, p.209-222, 1994.

RAJOPADHYE, M., et al. Forecasting uncertain hotel room demand, Information Sciences, v. 132, n. 1-4, p. 1-11, 2001.

SANDERS, R. N. The status of forecasting in manufacturing firms. Production and Inventory Management Journal; v 38, n 2, pg 32, 1997

SANTORO, M. C. Sistema de gestão de estoques de múltiplos itens em local único. 2006. 109p. Tese (Livre Docência) - Escola Politécnica, Universidade de São Paulo, São Paulo, 2006.

SILVER, E. A.; PETERSON, R. Decision Systems for Inventory Management and Production Planning. New York: John Wiley \& Sons, 1985.

SILVER, E. A. Operation Research in Inventory Management: A review and critique. Operations Research, v.29, n.4, p.628-645, 1981.

SNYDER, R. Forecasting sales of slow and fast moving inventories, European Journal of Operational Research, v. 140, n. 3, p. 684-699, 2002.

VINEYARD, M. L.; WILSON, E. S.; MEREDITH, J. R. Inventory and capacity management of natural gas under deregulation. Production and Inventory Management Journal. v. 38, n. 3; p. 57, 1997.

ORLICK, J. A. Material requirements planning: The new way of life in Production and Inventory Management, McGraw-Hill, New York, 1975. 